\title{
A Patent Analysis to Identify Emergent Topics and Convergence Fields: A Case Study of Chitosan
}

\author{
Worasak Klongthong ${ }^{1}$, Veera Muangsin ${ }^{2}$, Chupun Gowanit ${ }^{1}$ and Nongnuj Muangsin ${ }^{3, *}$ \\ 1 Technopreneurship and Innovation Management, Graduate School, Chulalongkorn University, \\ Bangkok 10330, Thailand; wklongthong@gmail.com (W.K.); chupun@gmail.com (C.G.) \\ 2 Department of Computer Engineering, Faculty of Engineering, Chulalongkorn University, \\ Bangkok 10330, Thailand; veera.m@chula.ac.th \\ 3 Department of Chemistry, Faculty of Science, Chulalongkorn University, Bangkok 10330, Thailand \\ * Correspondence: nongnuj.j@chula.ac.th
}

Citation: Klongthong, W.;

Muangsin, V.; Gowanit, C.;

Muangsin, N. A Patent Analysis to

Identify Emergent Topics and

Convergence Fields: A Case Study of

Chitosan. Sustainability 2021, 13, 9077.

https://doi.org/10.3390/su13169077

Academic Editor:

Konstantinos Dimos

Received: 31 May 2021

Accepted: 10 August 2021

Published: 13 August 2021

Publisher's Note: MDPI stays neutral with regard to jurisdictional claims in published maps and institutional affiliations.

Copyright: (c) 2021 by the authors. Licensee MDPI, Basel, Switzerland. This article is an open access article distributed under the terms and conditions of the Creative Commons Attribution (CC BY) license (https:// creativecommons.org/licenses/by/ $4.0 /)$.

\begin{abstract}
Identifying emerging technology trends from patents helps to understand the status of the technology commercialization or utilization. It could provide research insights leading to advanced technological innovations that stimulate socially responsible research to address human dietary and medical needs. However, few studies have investigated emerging chitosan applications using patents. In this study, we report the application of a patent bibliometric predictive intelligence (PBPI) model to identify emergent topics and technology convergence related to chitosan applications from patents in the International Patent Classification system. Text mining was used to extract patterns from 5001 patents and each term was assigned an emergent score, following which we traced growth patterns, examined relationships between IPCs, emergent topics, and patents using correlation analysis and principal component analysis, and conducted matrix and cluster mapping analysis to understand industrial applications and explore patterns of technological convergence. Five major terms emerged in association with ascending and newly emergent topics over the last 13 years: "shelf life," "antibacterial," "good safety," "absorbing water," and "auxiliary materials." These topics were closely linked with research in the biomedical and food production and preservation industries. A network analysis indicated that "antibacterial" terms exhibited the highest degree of convergence, followed by "shelf life." These findings can inform strategies to determine new directions for chitosan research.
\end{abstract}

Keywords: chitosan; emerging technology; technological convergence; food industry; biomedical applications; patent analysis; bibliometric analysis

\section{Introduction}

Over the last 2-3 decades, we have seen an increased blurring of the borders between industries and scientific disciplines, such that technologies developed in one area have come to significantly influence those in others. Broadly referred to as technological convergence [1], this rapidly growing phenomenon is driving the development innovations that confer significant social as well as commercial benefits [2].

Researchers in the academic and industrial spheres have highlighted the role of emerging technologies (ET) in technological convergence. The successful anticipation of technological convergence and emerging technologies empowers firms to form strategic alliances and invest in research and development (R\&D) initiatives that will enable them to glean market patterns and plan the direction of technology development, thereby achieving a competitive advantage. Similarly academic and research institutions seek to forecast emerging developments in order to strategize funding and collaborations that will put them at the forefront of scientific innovation. 
Various approaches to the analysis of patents and scientific publications include the use of bibliometrics and text mining techniques to identify and forecast the importance of technologies in the early stages of development and convergence [3-8]. In particular, patents provide quantitative and objective details on current and emerging technological trends, evolution, and growth [9]. Moreover, identifying the parties involved in obtaining patents in particular areas can yield information regarding interactions and convergences among different technologies as well as highlight the emergence and growth of research networks at the national, institutional, and individual levels [3,5,10-12].

The use of patents to uncover emerging technologies and convergence patterns has several advantages over using scientific publications alone. Scientists and companies file patent applications to secure their inventions long before new developments are introduced to the general public [4]. Patents provide descriptions of the technological aspects and potential applications of inventions in great detail, whereas the use of technologies may already be established by the time scientific articles are published. Patents also provide information on knowledge transfer and spillover between technologies and scientific disciplines, for example, in the form of references to related non-patent literature such as scientific articles or conference proceedings as well as information on linkages between distinct industrial sectors [6]. For example, Lee et al. used Big Data technologies to search large patent datasets to derive technology linkages and predict future convergence patterns based on the International Patent Classification (IPC) cooccurrence network [8], and Karvonen and Kässi [6] used patent citations to non-patent literature to analyze potential technological convergence between emerging business sectors in the paper and electronics industries. Similarly, Curran and Leker [4] developed an IPC co-classification-based approach to monitor convergence between in the pharmaceutical and food industries as well as the information technologies, consumer electronics, and telecommunications sectors.

Among a plethora of areas in which emerging technologies play a pivotal role, the development of biopolymers has accelerated in recent years. A biopolymer is defined as a polymer made under natural conditions using materials from living organisms. Examples of such materials are plants, fossils, animals, microbes, and agricultural wastes. Processive enzymes synthesize biopolymers by linking up building blocks to form a larger molecule with higher molecular weight. Examples of building blocks linked up are amino acids, sugars, and hydroxyl fatty acids. Among biopolymer materials, starch and cellulose are the most interesting and fascinating. There has, however, been increasing attention to biopolymers (complex and hydrocarbon in nature) produced by bacteria and fungi. These include xanthan, curdlan, pullulan, hyaluronic acid, and chitin/chitosan [13-16]. Biopolymers are substantially more sustainable than fossil-fuel-derived polymers due to their immunogenic properties, which endow them with the ability to degrade when exposed to natural enzymes [17]. Produced by microorganisms and biomaterials such as collagen, chitin, silk, and starch [18], natural biopolymers are biocompatible, biodegradable, and non-toxic; they are safer for humans and animals than synthetic polymers and more environmentally sustainable. As such, they have increasingly been used in the food industry, such as edible films and packaging $[19,20]$, water purification, and biomedical engineering [21-23].

For example, the biopolymer chitosan has varied applications in the medical, pharmaceutical, healthcare, cosmetic, and agricultural industries, as well as food and beverage manufacturing $[17,24-26]$. Chitosan is obtained by produced by the deacetylation of chitin, either through a solid-state reaction entailing partial deacetylation under alkaline conditions or treatment with concentrated aqueous sodium hydroxide to achieve enzymatic hydrolysis in presence of chitin deacetylase [25]. The raw material for chitosan synthesis is waste from the fishery industry, specifically chitin from the shells of shrimp, crawfish, and other crustaceans. Thus, chitosan synthesis transforms bio-waste into a value-added product that fosters environmental sustainability while also generating economic growth.

Through chemical modifications, chitosan generates products for medical and pharmaceutical applications such as drug delivery systems, regenerative and antiviral medicine, 
and wound dressings. Chitosan is a matrix material that promotes the uniform stabilization and dispersion of nanoparticles in polymer environments, and chitosan-based nanomaterials have improved physical and chemical properties compared to pure chitosan, including superior tensile strength, mechanical properties, conductivity, and increased surface area, porosity, and photo-luminescence [26]. Moreover, various methods can be used to enable chitosan nanoparticles to release active ingredients in a sustained manner over a prolonged time period, and chitosan can be functionalized to enhance its adsorption capacity [17]. Chitosan has also found various applications in the food industry. In its pure form, it can be dissolved in dilute acid solutions (e.g., hydrochloric acid) and fabricated into edible films to preserve fruits and vegetables, thereby prolonging shelf life by preventing microbial growth and maintaining antioxidant activity as well as nutraceutical qualities, and vacuum packaging can be combined with pure chitosan films to preserve fish and meats [24]. As such, it is unsurprising that various companies in the food, biomedical, and biotechnological industries have devoted substantial efforts to researching various applications of chitosan-based products.

Analyzing patents to identify emerging trends in chitosan applications could provide research insights leading to advanced technological innovations that stimulate socially responsible research that generates revenue while also contributing to the development of sustainable solutions to address human dietary and medical needs. However, to date, few studies have used bibliometric methods to investigate emerging chitosan applications, and those that have done so have generally limited their focus to biomedical innovations [17]. Accordingly, this research expanded the disciplinary scope and applied a patent bibliometric predictive intelligence (PBPI) model to identify emergent topics and areas of technological convergence related to applications of chitosan technology using patent analysis. In doing so, it gleans current trends and forecasts upcoming innovations and research directions in chitosan applications across fields.

\section{Theoretical Background}

\subsection{Emerging Technology}

The term "emergence" is used in diverse ways; however, the concept is rarely defined in the literature $[27,28]$. Nonetheless, novelty and growth are the properties most associated with emergence across the literature. For example, Goldstein [28] characterized emergence as embodying radical novelty, coherence, and integration, and dynamism in a manner that is highly perceptible and recognizable. In this vein, emerging technologies (ET) can be defined as technologies that may come to have significant social and/or economic impacts but are currently in the early phase of their development or will materialize over the next $5-10$ years.

Emerging technology research is increasingly attracting attention as an indicator that can yield insights into scientific breakthroughs as well as commercial innovations. At the micro level, ET research seeks practical measures to distinguish prevalent sub-topics and thereby determine the direction of R\&D policy, technology opportunities analyses, and innovation to enable the transformation of industries or the development of new commercial paths [29-32]. At the macro level, ET research aims to uncover innovations that can contribute to economic growth and improved social conditions.

Prediction has been demonstrated to be an effective tool for anticipating and understanding the potential trends and impacts of technological change [31]; however, forecasting emerging technologies is a challenging endeavor. Publication and patent data are widely analyzed to forecast emerging technologies [33], and emergent topics can be qualitatively derived from expert opinion or quantitatively identified through sophisticated bibliometric analyses. The latter often complements or confirms expert assessments and entails utilizing text or data mining to search for intensifying patterns of publications or patents in a specific field or topic or through a co-occurrence analysis of keywords (co-keywords), citations (co-citations), and/or authors [34-38]. 
Two main directions predominate bibliometric data mining: (1) identifying existing technologies in the early stages of development and (2) predictive analysis that recognizes new technologies prior to their actual emergence. Regarding the former approach, Upham and Small used the ISI database to generate co-citations and thereby identify the most prolific emergent science and technology research topics from 1999 to 2004 [39], and Goeldner, Herstatt, and Tietze [7] used bibliographic and network analyses of PATSTAT patent and ISI Web of Science publication data to identify active players in care robotics research data at the national, institutional, and individual levels. As an example of the latter direction, Porter et al. illustrated an implemented algorithm to calculate emergence scores from topical keywords in abstract records and elucidated steps for generating research and development $(R \& D)$ indicators to highlight prevalent terms and related key players [40]. Geum and Kim [41] utilized the less commonly used keygraph method to detect infrequent yet meaningful keywords in patents and thereby identify promising opportunities for technological innovation.

High emergent scores provide a sense of frontier R\&D interests as well as organizational strategic directions and industry opportunities in a given domain [40]. In sum, technological emergence is characterized by four key attributes: (1) social and economic impacts, i.e., the ET will potentially benefit a wide swathe of economic sectors and/or social groups [2]; (2) newness or innovativeness that may create a new industry or transform existing ones [42]; (3) growth, i.e., increasing R\&D outputs and ongoing development [43,44]; and (4) involving communities of practice, implying that multiple players, not all of whom are within a single research unit or entity, are collaborating in some manner, e.g., citation connections in $R \& D$ literature analyses [45].

\subsection{Technological Forecasting Using Patent and Publication Analysis}

To monitor technological trends and forecast emerging technology, researchers have been using bibliometric analysis of many data sources, especially research articles and patents. Most bibliometric analysis works are based on one type of data source, although using multiple sources has been reported and recommended as they are complementary [3,7,46-48]. In comparison, publications and patents capture different stages of the research-to-product pathway. Moreover, it has been observed that publications in scientific journals are dominated by universities and research institutes while patenting activities are dominated by private companies.

Regarding the benefits of patent analysis, patents have applications to various tactical and strategic assessment. Firstly, patent analysis helps in technology assessment. Patents can serve as 'indicators', or indirect measures, of company commitment to technology. For example, if one company has more patents than another, this suggests that the first firm has a stronger commitment to technology development. It aims to measure capabilities to allow tracking of changes over time. Moreover, patents reflect the ability of a company to transform scientific results into technological applications. Thus, patents can serve as the sources for economic potential analysis together with legal status and protection [46].

The footprints on innovation pathway start from research in scientific articles, technology development by patents, and product innovation on the market [47]. Most scientific publications contain mainly basic research findings, whereas patent documents contain mainly technical solutions or technology [48]. The determination of emerging technologies from patent analysis could provide useful information for future market opportunities through technology development. Furthermore, patent analysis helps in the determination of the state of the art, the identification of trends, and the possibility of detecting innovation breakthroughs. 
However, patent analysis alone has some limitations. Firstly, from the patent filing date, it takes on average 18 months for the patent to be granted or published [48]. This can lead to a time-lag of analysis when we collect patents from the patent database. Secondly, not all technology development is patented. Firms can use other strategies for intellectual property (IP) protection, therefore, that information cannot be analyzed. Finally, quantitative analysis of patents may not measure the patent quality. However, the statistical analysis of patents is one powerful method for identifying technology competitiveness and emerging technologies at the first stage to monitor activities. Qualitative analysis such as expert interpretation and evaluation can be further taken to mitigate the weakness of the patent analysis.

\subsection{Technological Convergence Based on International Patent Classification}

The use of patent classification systems is a key part of analyzing technology trends and identifying possible opportunities. The current patent classification system is complex and hierarchical, comprising the descending levels of section, class, subclass, group, and subgroup (Figure 1). Patents contain substantial information about innovation phenomena, and patent co-classification analysis has been extensively used in numerous previous studies [49-53]. Curran and Leker [4] analyzed patent co-classification by investigating overlaps of patent classes to monitor technological convergence in different fields of the ICT sector. Lee et al. [54] integrated an analytic network process (ANP) and social network analysis to investigate the role of intermediaries in fostering innovation in the small and medium enterprise (SME) sector. Ko et al. [55] combined patent co-classification, decisionmaking trial and evaluation laboratory (DEMATEL), and network analysis to analyze technology impact networks and the intermediation of technology areas. Han and Sohn [56] integrated association rule and social network analyses of patent classifications to identify core technologies playing an important role in technology convergence. In their use of patent co-classification to monitor technological convergence, Yun and Geum [57] employed several indexes to measure the fluctuation and continuity of patent overlaps as a means to analyze dynamic technological convergence. Gao et al. [58] revealed a development trends in blockchain-based 5G network by applying network topology analysis to build an IPC network topology diagram through node global and local topology characteristics. They point out hotspots of IPC technology research and the characteristics of the technology relationship system.

\section{Section Sub-class Sub-Group

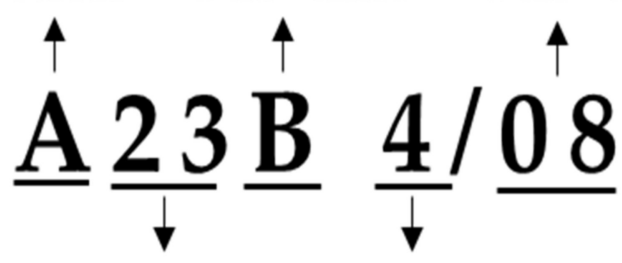 \\ Class Group}

Figure 1. Structure of patent classification system.

\section{Methodology and Data}

This study applied a patent bibliometric predictive intelligence (PBPI) model adapted from the emergent technology identification approach published in previous studies to identify emergent topics and technology convergence related to chitosan applications (Figure 2) [17,40,42,59,60]. 


\section{Technological database}
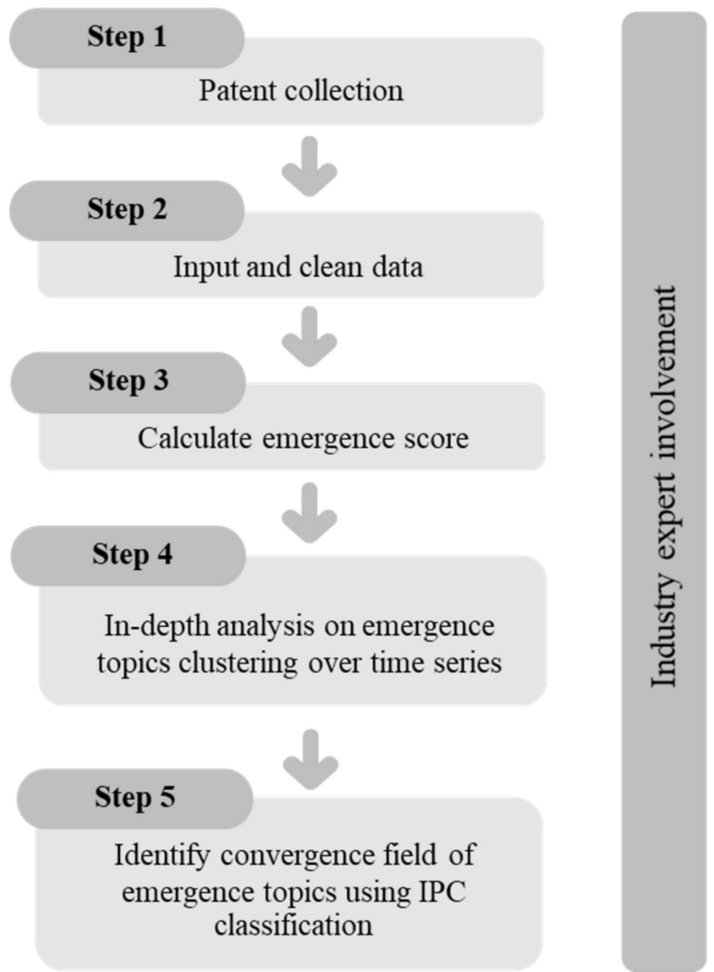

"Interested Area" from TotalPatent One

1. Import into VantagePoint

2. Cleaning data

1. Title (NLP)

2. Abstract (NLP)

1. Growth trend

2. Emergence topics

3. Emergence topics comparison

4. Factor map

1. Matrix of convergence field

2. Cluster map

Figure 2. The patent bibliometric predictive intelligence (PBPI) framework.

This model reflects a bibliometric-based approach to measure emergence by tabulating and tracking patterns in patents. 'Tech mining' is a term that we have adopted to describe our use of text mining tools to extract useful intelligence from science, technology, and innovation (ST\&I) resources [61]. Tracing technological trends is fostered by text analyses of topical content to consolidate important terms and phrases relating to a given concept or theme $[57,62,63]$. That topical content can then be tracked over time to glean evolutionary pathways [64].

Firstly, the process began by using several queries suggested by experts to retrieve a set of research related to chitosan in patent records from the TotalPatent One database (www.totalpatentone.com, accessed on 2 May 2021). A total of 5001 patents published from 1961 to 2020 was retrieved from the database.

Secondly, all patents were subjected to text mining, whereby VantagePoint software version 2020 was utilized to extract title and abstract patterns related to chitosan applications, following which the data were cleaned and words and phrases from titles and abstracts were merged before running the results.

Thirdly, we calculated emergence scores from the words and phrases from the third step, for which we developed a custom "emergence indicator" script using VantagePoint software. The script terms that met these thresholds were adapted from [17,59] as follows: (a) must appear in records for at least three years; (b) must appear in at least seven records; (c) the ratio of records containing the term in the active period to those in the base period must be at least 2:1; (d) the term cannot appear in 15\% or more of the base period records; and (e) terms must have more than one author that does not share the same record set. These thresholds target the four attributes of emergence that we emphasized: (1) enduring societal impact; (2) newness/novelty; (3) growth; and (4) communities of practice. Thresholds (a) and (b) aim to ensure a level of societal impact whereby the topic does not occur only in one or two years and then disappears, and the topic relates to 
an issue of global interest, whereas thresholds (c) and (d) capture newness and growth whereby the term increasingly appears later in the data period. Threshold (e) ensures that research communities comprising multiple authors from more than one institution have engaged the topic. The specific levels chosen were based on our experimentation with the test datasets described herein as well as several others. However, the script enables a user to vary the thresholds for a small dataset, and one could reduce the requirement of at least seven total records containing the term. We then applied formulations based on Wang et al. [59]. For elaboration, the script terms in Vantagepoint with indicators of how our four attributes of emergence were calculated and run as a script in Vantagepoint exactly: the process started with a first script term, i.e., the t-term, which refers to a continuous ten unit-year period in which the numbers 1-10 respectively denote those ten units. Term $t-1$ to $t-3$ was taken as a base period ( $t_{\text {base }}$ ), and $t-4$ to $t-10$ was taken as the active period $\left(t_{\text {active }}\right)$. To specify term $\mathrm{i}: \mathrm{n}_{\mathrm{it}}$ : number of records contain term $\mathrm{i}$ in time $\mathrm{t}$;

$$
x=\left\{\begin{array}{cc}
1 & \text { if term } \mathrm{i} \text { appears in time period } \mathrm{t} \\
0 & \text { otherwise }
\end{array}\right.
$$

$\mathrm{N}_{\mathrm{t}}$ : number of records in time period $t_{\text {active }}$ is the set of cracking keywords and phrases (title and abstract) for which we use term i;

$$
|\mathrm{A}|=\mathrm{m}, \mathrm{A}=\left\{\mathrm{a}_{1}, \ldots, a_{\mathrm{m}}\right\}, 1 \leq \mathrm{j} \leq \mathrm{m}, 1 \leq \mathrm{k} \leq \mathrm{m}, \mathrm{j} \neq \mathrm{k} ; \mathrm{y}_{\mathrm{jk}}=\left\{\begin{array}{cc}
0 & \mathrm{a}_{\mathrm{j}} \text { and } \mathrm{a}_{\mathrm{k}} \text { co author one record } \\
1 & \text { otherwise }
\end{array}\right.
$$

Enduring societal impact: A term must appear in at least one record during three time periods (years) and at least seven total records in order to meet the specified "enduring impact societal impact" attribute.

$$
\text { if } \sum_{t} x_{i t} \geq 3 \text { and } \sum_{t} n_{i t} \geq 7
$$

Newness: The term cannot appear in $15 \%$ or more of the base period records in order to meet the specified "newness" attribute.

$$
\text { if } \frac{\sum_{\mathrm{t}=1}^{3} \mathrm{n}_{\mathrm{it}}}{\sum_{\mathrm{t}=1}^{10} \mathrm{n}_{\mathrm{it}}} \leq 0.15
$$

Growth: The ratio of records containing the term in the active period to those in the base period must be at least 2:1 in order to meet the specified "growth" attribute.

$$
\text { if } \sum_{\mathrm{t}=4}^{10} \mathrm{n}_{\mathrm{it}} \geq 2 \times \sum_{\mathrm{t}=1}^{3} \mathrm{n}_{\mathrm{it}}
$$

Community: The terms need to be used by more than one author who is not listed as a co-author on the same set of records in order to meet the specified "community" attribute.

$$
\mathrm{m} \geq 2 \text { and } \sum_{\mathrm{j}=1}^{\mathrm{m}} \sum_{k \neq j} \mathrm{y}_{\mathrm{jk}} \geq 1
$$

Based on the above, we applied the formulation based on Porter et al. [40] to calculate the emergence score (Escore) as

$$
\text { EScore }=2 \times \text { Active Period Trend }+ \text { Recent Trend }+ \text { Slope }
$$


For a given term with seven periods of active data (the default), the calculations of EScore for term i would be

$$
\begin{aligned}
\text { Active Trend } & =\left(\sum_{\mathrm{t}=5}^{7} \frac{\mathrm{n}_{\mathrm{it}}}{\sqrt{\mathrm{N}_{\mathrm{t}}}}-\sum_{\mathrm{t}=1}^{3} \frac{\mathrm{n}_{\mathrm{it}}}{\sqrt{\mathrm{N}_{\mathrm{t}}}}\right) \\
\text { Recent Trend }_{\mathrm{i}} & =\left(\sum_{\mathrm{t}=6}^{7} \frac{\mathrm{n}_{\mathrm{it}}}{\sqrt{\mathrm{N}_{\mathrm{t}}}}-\sum_{\mathrm{t}=4}^{5} \frac{\mathrm{n}_{\mathrm{it}}}{\sqrt{\mathrm{N}_{\mathrm{t}}}}\right) \times 10 \\
\text { Slope }_{\mathrm{i}} & =\frac{\frac{\mathrm{n}_{\mathrm{i} 10}}{\sqrt{\mathrm{N}_{10}}}-\frac{\mathrm{n}_{\mathrm{i} 7}}{\sqrt{\mathrm{N}_{7}}}}{3} \times 10
\end{aligned}
$$

$$
\text { EScore }_{i}=2 \times \text { Active Trend }_{i}+\text { Recent Trend }_{i}+\text { Slope }_{i}
$$

Based on the formula in Equation (7), in order to identify emergent topics related to chitosan, we used various 10-year test periods (including 2008-2017, 2009-2018, 2010-2019, and 2011-2020) to understand the evolution of technology over time and compare the development of the technology. A 10-year test period consists of a 3-year base period plus a 7-year active period $[40,59]$. We examined several levels of the resulting term scores for various datasets, settling on a threshold of 1.77 for a term to be considered emergent. If EScore $_{i} \geq 1.77$, the value 1.77 was chosen based on empirical observations. A reasonable threshold was judged to fall between EScores of 1.5 and 2. We selected 1.77 as the square root of Pi.

Once the emerging topics were identified, we investigated the details of top patents in particular areas to trace patterns of technological development. We then performed a Pearson correlation analysis to understand relationships between the numbers of International Patent Classifications (IPCs), emergent topics, and records, following which we used VantagePoint to conduct a principal component analysis (PCA) to examine topical co-occurrence among the emergent terms from the most recent 10-year period of the dataset (2011-2020). Finally, we performed a matrix and cluster mapping analysis of the patent classifications to understand their industrial applications and explore patterns of technological convergence.

\section{Results}

\subsection{Growth Trend}

The number of patent publications per year was collected from 1961 to 2020 in order to identify the emerging range for further analysis. As shown in Figure 3, the trend line fits with the exponential curve whereby $y$ represents numbers of publications and $x$ represents year with $R^{2}=96.6 \%$. The number of patent publications clearly evinces an increase from 2008. Notably, the compound annual growth rate (CAGR) was observed to nearly double (15.6\%) from 2008 to 2020, when there was a significant increase in publications. Thus, we selected the time period from 2008 to 2020 for further analysis to identify emergent topics and technology convergence.

Figure 4 shows the numbers of patents in four particular ranges (2008-2017, 2009-2018, 2010-2019, and 2011-2020) for analysis. As shown, the evolution of patent quantities in the four 10-year periods gradually increased from 2590 to 4087 patents. It can be seen that the chitosan field has been an attractive research area, and multiple companies, universities, and institutes have sought legal protection of applications developed from this biopolymer. 


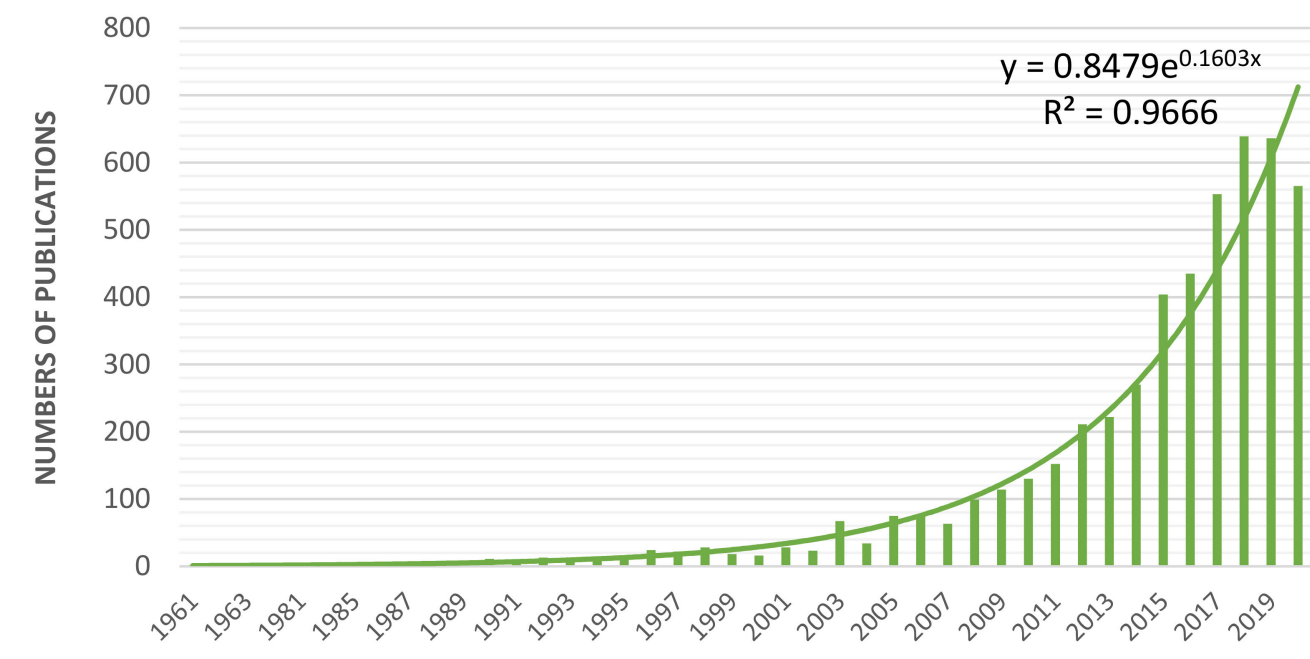

Figure 3. The numbers of patent publications.

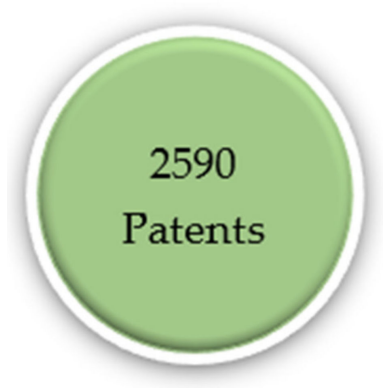

2008-2017

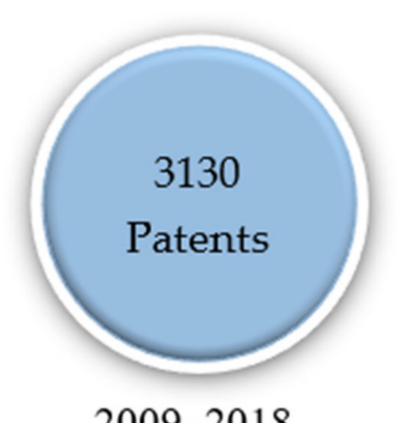

2009-2018

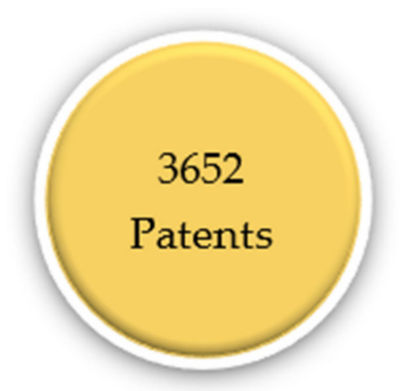

2010-2019

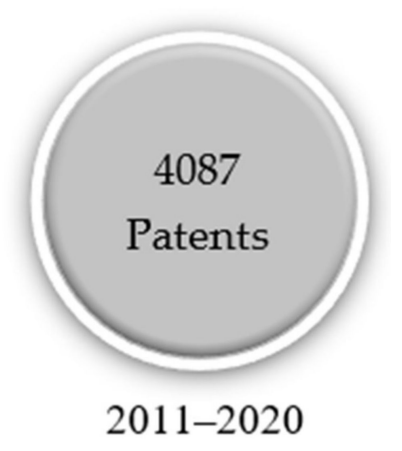

Figure 4. Numbers of patents to analyze an emergent chitosan applications.

\subsection{Emergent Topics Analysis}

4.2.1. Emergent Terms and Domains

Table 1 presents the top 20 emergence scores according to the topic. Our experts concluded that most of the topics are related to each other, and we categorized them into three major emergent domains: (1) an ascending group comprising emergent topics for which the E-scores increased over time; (2) a descending group constituting topics for which the E-scores decreased/disappear over time; and (3) newly emerging topics that have only appeared in the past two periods of recent years (the 2010-2019 and 2011-2020 periods) and are likely to experience further growth in the future.

In the first group, the two top emergent terms are "shelf life" and "antibacterial." The E-scores for "shelf life" increased from the first 10-period (3.991) to the most recent period (6.653), which means that this term has become of interest over time. For example, Patent no. CN106046402B describes an edible chitosan-based package membrane that has a wide range of applications in industrial production. This chitosan composite film evinces an improved mechanical performance over other chitosan packaging forms, and due to the addition of natural antibacterial components, it can inhibit the reproduction of microorganisms and thereby prolong the shelf life of the foods [65]. Similarly, Patent no. CN105166010A outlines an invention that prolongs the shelf life of egg products using double layers comprised of a prepared PVA-whey protein nano-antibacterial coating film solution and a chitosan-PVA nano-antibacterial coating film solution. This safe, nontoxic, and degradable substrate improves the quality of egg products, is easy and convenient to prepare and use, and requires low production energy, which results in substantial economic benefits for the egg product industry [66]. Chen et al. [67] obtained another invention with antibacterial applications, which uses iodo-cosanol and ethylenediamine as raw materials 
to synthesize nitrogen-doped and iodine-doped carbon dots, which are then fixed onto the surfaces of chitosan molecules to form a compound that is mixed with hydrogen peroxide. Aimed toward the tobacco industry, this agent is touted as being safe, environment-friendly, and effective at producing a "synergistic antibacterial effect".

We identified only one interesting emergent term in the second group: "chitosan film." This term appeared in the first period and has already disappeared in the most recent period. Even though this term disappeared in the most recent period, this term can be included or merged into other terms such as "shelf life" and "composite film". This is because the chitosan film is mainly applied for the extension of food shelf life. Patent no. CN106436473B encompasses a compound bacteriostatic food wrapping film produced from chitosans with varying fungistatic effects, which are combined with the emulsifier Tween and the bacteriostatic agent nisin to form a chitosan film with relatively high fracture strain [68]. The resulting film can be used to wrap pastry foods and preserved fruit products so that they meet state-specified freshness requirements without adding preservatives. A technique in Patent no. CN106832437B covers a silver-loaded nano cellulose-chitosan composite film that has broad application prospects in antibacterial wound dressings, food packaging, and other industries. The mechanical properties of the nano cellulose are stated to improve the mechanical strength problem of the chitosan film, and the silver-loading operation enhances chitosan's antibacterial properties [69].

Major terms associated with the last group are "good safety", "absorbing water", and "auxiliary materials". These terms appeared in the two most recent periods of time. It means that there is possibility of utilizing these terms in the real applications. Patent no. CN107050502B covers a three-dimensional network polymer hydrogel adhesive sponge with chitosan as its skeleton, superabsorbent polymer as its branched chain, and a macromolecule or polymer with flexible structure as its cross-linking agent. Prepared by a simple, one-pot method, the sponge is described as being more effective than existing products in the first-aid emergency hemostasis of large arteriovenous hemorrhage. Other advantages touted in the application include low production cost, outstanding hemostatic effect, no heat production or residue, and significant medical value and industrial potential [70].

Zhang et al. [71], for another invention with biomedical applications, obtained a multilayer wound dressing patch with moisture absorption and vapor-permeable qualities comprised of chitosan, chitooligosaccharide, oxidized sodium alginate, gelatin, carboxymethylcellulose sodium, and purified water. Advantages of the invention include short onset and long action times as well as hemostasis, analgesic and healing promotion effects, good breathability, and a waterproof layer that keeps the skin dry. The application also highlights the patch's biocompatibility; thus, it can be attached to the surface of the human body for a lengthy time with no discomfort or allergic reaction. Similarly, Jin et al. [72] invented a multi-layered composite functional surgical dressing formed by mixing chitosan fiber and viscose. This three-layer laminate has an upper functional layer, a middle water-absorbing layer, and a lower protective layer. The product is described as having high biocompatibility, an antibacterial rate up to 96.7 percent, a liquid absorption rate of $1259 \%$, and a waterproofing grade up to level 5 . The surgical dressing can be used for operative incisions, burns, ulcers, and other skin injuries, and the production process is simple, low-cost, and environmentally friendly.

Cui et al. [73] presents an antiviral soil-fixing dust suppressant prepared from water carboxymethyl chitosan, polyacrylamide, sodium alginate, sodium dodecyl sulfate, and carboxymethyl cellulose. The product represents an "optimal combination" of natural marine organisms as the main raw materials and industrial byproducts as auxiliary materials that is biodegradable. This invention has both agricultural and biomedical applications; it is capable of promoting plant growth via sand prevention and ecological slope protection, and it can also control the transmission of bacteria and viruses. Another agricultural product, which is covered by the patent of Wang et al. [74], is an organic fertilizer enhanced by auxiliary materials comprising a surfactant, chitin, magnet powder, humic acid, and a microbial preparation. This environmentally friendly fertilizer provides comprehensive nutrition 
and the production process is simple and quick. Experiments have demonstrated that the fertilizer improves the yield and the quality of crops while reducing input and waste.

Table 1. Top 20 emergent topics and scores.

\begin{tabular}{|c|c|c|c|}
\hline \multicolumn{2}{|c|}{ 2008-2017 } & \multicolumn{2}{|c|}{ 2009-2018 } \\
\hline Emergent Topics & E-Score & Emergent Topics & E-Score \\
\hline service life & 12.107 & effective components & 7.551 \\
\hline disease prevention & 8.118 & disease prevention & 6.606 \\
\hline tensile strength & 7.725 & environmental friendliness & 4.468 \\
\hline coating & 6.455 & antibacterial performance & 4.181 \\
\hline agricultural products & 4.488 & shelf life & 4.151 \\
\hline fresh keeping & 4.007 & skin care products & 3.682 \\
\hline shelf life & 3.991 & antibacterial & 3.511 \\
\hline food safety & 3.826 & treatment & 3.364 \\
\hline healthcare products & 3.615 & packaging materials & 3.198 \\
\hline mechanical strength & 3.318 & fresh-keeping agent & 3.117 \\
\hline food packaging & 3.284 & antibacterial effect & 2.774 \\
\hline antibacterial agent & 2.926 & chitosan film & 2.611 \\
\hline wear resistance & 2.886 & drug resistance & 2.518 \\
\hline stress resistance & 2.713 & reducing agent & 2.496 \\
\hline water resistance & 2.506 & animal production & 2.357 \\
\hline chitosan film & 2.234 & microorganisms & 2.192 \\
\hline healing & 2.122 & moisture absorption & 2.171 \\
\hline wound surface & 2.021 & auxiliary agents & 2.025 \\
\hline good adsorption effect & 1.86 & stress resistance & 2.004 \\
\hline coating material & 1.855 & biomedical application & 1.921 \\
\hline \multicolumn{2}{|c|}{ 2010-2019 } & \multicolumn{2}{|c|}{$2011-2020$} \\
\hline Emergent Topics & E-Score & Emergent Topics & E-Score \\
\hline shelf life & 5.099 & shelf life & 6.653 \\
\hline water absorption & 4.231 & antibacterial property & 6.425 \\
\hline aging & 3.982 & good safety & 5.075 \\
\hline biodegradability & 3.879 & biomass raw materials & 4.424 \\
\hline good safety & 3.661 & oxidation resistance & 4.000 \\
\hline antibacterial effect & 3.597 & antibacterial effect & 3.753 \\
\hline biotechnology & 3.256 & adsorption performance & 3.464 \\
\hline fresh keeping & 2.927 & auxiliary materials & 3.355 \\
\hline water body & 2.841 & thermal stability & 3.339 \\
\hline antibacterial & 2.813 & biocompatibility & 3.283 \\
\hline chitosan film & 2.476 & storage stability & 3.176 \\
\hline absorbing water & 2.44 & composite film & 3.083 \\
\hline biomedical materials & 2.234 & antibacterial performance & 2.752 \\
\hline biomedical application & 2.212 & biodegradable materials & 2.661 \\
\hline waterproof & 2.123 & electrochemical sensor & 2.618 \\
\hline skin care products & 1.944 & food materials & 2.612 \\
\hline reducing agent & 1.903 & absorbing water & 2.531 \\
\hline thickening agent & 1.897 & health care products & 2.09 \\
\hline auxiliary materials & 1.886 & good film-forming property & 2.029 \\
\hline antioxidant activity & 1.828 & encapsulation efficiency & 1.885 \\
\hline
\end{tabular}

\subsubsection{Topical Correlations}

The Pearson correlation analysis indicated no significant correlation between the numbers of IPCs and emergent topics; however, there is a large and significant positive correlation between the number of emergent topics and the number of records $(r=0.993$, $p=0.007$; Table 2). One possible explanation for this finding is that most inventors seek to further investigate the applications of products in existing IPCs rather than initiating new classifications. 
Table 2. Correlation analysis.

\begin{tabular}{cccc}
\hline & IPC & Record & Emergent Topics \\
\hline IPC & - & -0.904 & -0.918 \\
Record & - & - & $0.993^{*}$ \\
\hline
\end{tabular}

* Correlation is significant at the 0.01 level (2-tailed).

Figure 5 illustrates the results of the PCA. The node sizes denote relative numbers of records and the linkage lines represent the degree of relationship among nodes based on a path-erasing algorithm. Heavier lines indicate stronger relationships, whereas dashed lines represent weaker relationships. The absence of a linkage line denotes that the degree of relationship is below the threshold limit. The PCA found that 16 highly emergent topics illustrate nodes or clusters, each of which represents a set of terms that tend to appear together. We predict that research of these highly emergent topics is likely to remain especially active over the next two to three years.

\subsection{Technology Convergence and Applications Based on Emergent Topics}

\subsubsection{Applications of Emergent Topics}

The definition of IPC classifications and sub-classifications can be found on the WIPO website [75]. A cross-correlation matrix of emergence topics and IPC classifications shows the intensity of topical convergence in each field of application. Table 3 (2011-2020) shows the correspondence between top emergent chitosan topics and IPC applications. Table 3 shows numbers of records of patents related to emergent topics. The intensity of the color corresponds to the number of records, representing that higher numbers of records yield higher numbers of interest inventors. The most popular application is $\mathrm{A} 61 \mathrm{~K}$, which refers to "human necessities" served by various applications and sub-applications in medicine, dentistry, veterinary science, and hygiene.

Two additional popular fields in "human necessities" applications are A23B and A23L, both of which are related to food industry applications. For example, "shelf life" contains 26 patent records corresponding to A23B, including the preservation, chemical ripening, or canning of meat, fish, eggs, fruit, vegetables, and edible seeds, as well as 14 records for A23L, which encompasses the preparation or treatment (e.g., cooking, modification of nutritive qualities, and physical treatment) of foodstuffs and beverages not covered by other subclasses (A23B-A23J).

In addition, nine records related to "good safety" and five related to "absorbing water" converge with A61L, which encompasses methods or apparatuses related to the disinfection, sterilization, and deodorization of air and general objects as well as bandages, dressings, absorbent pads, or surgical articles.

The three most popular emergence topics are "shelf life" which accounts for 26 records of A23B preservations for foods; "health care products", which accounts for 24 A61K preparations for medical, dental, or hygiene purposes; and "biocompatibility", which covers 19 records in A61L.

We further conducted an in-depth analysis of the top four emergent topics from the "ascending" and newly emerging domains defined in Section 4.2, namely "shelf life", "good safety", "absorbing water", and "auxiliary materials" to investigate a variety of convergence fields in each term. 


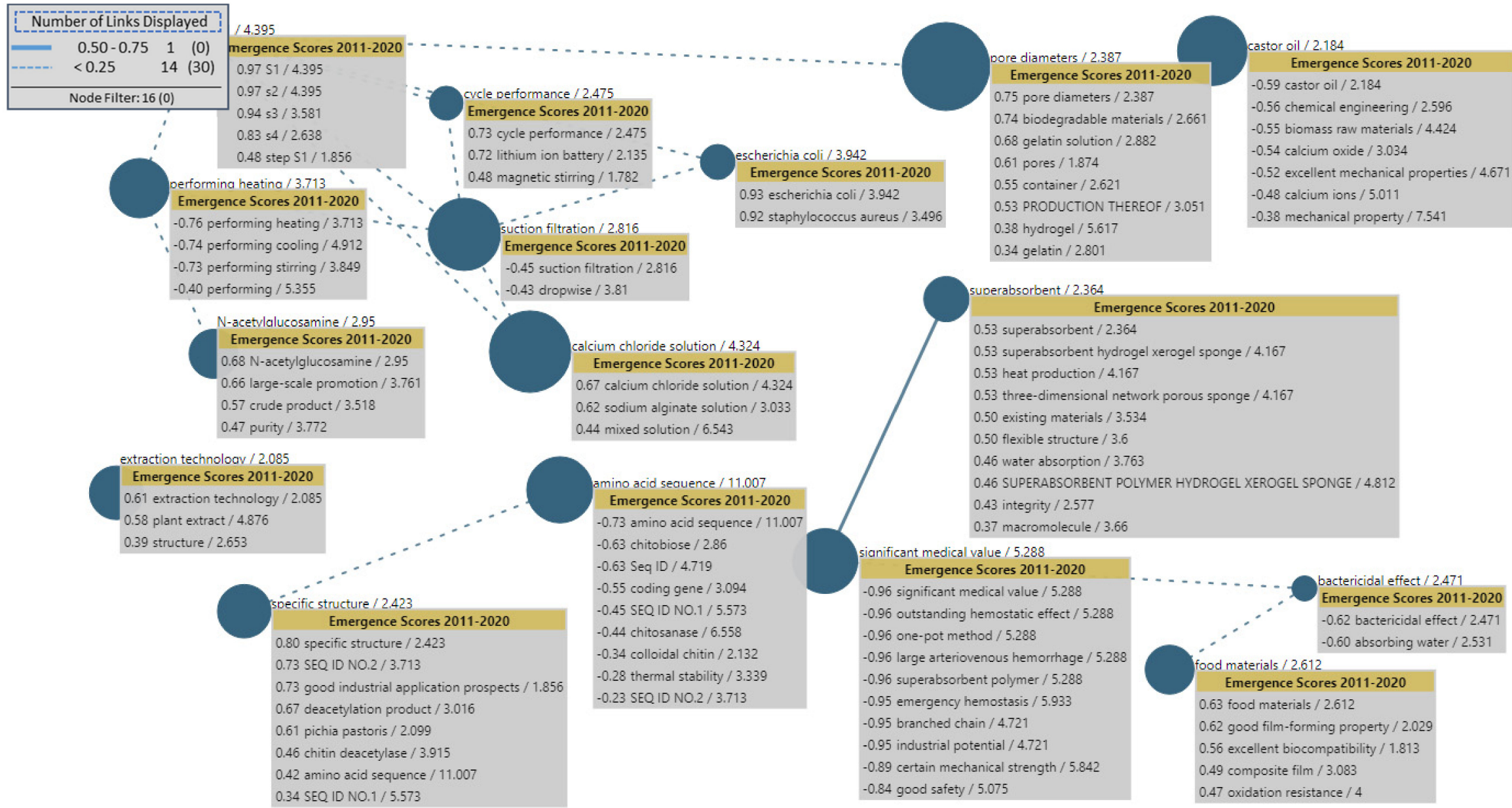

Figure 5. Factor map of emergent topics (2011-2020). 
Table 3. Top emergent topics and applications.

\begin{tabular}{|c|c|c|c|c|c|c|c|c|c|c|c|c|c|c|c|c|c|c|c|c|}
\hline IPC Classification (Convergence Field) * & 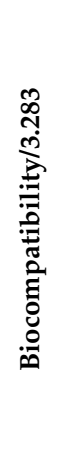 & 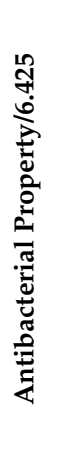 & 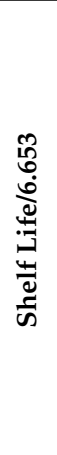 & 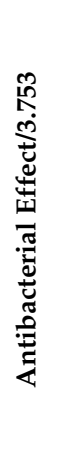 & 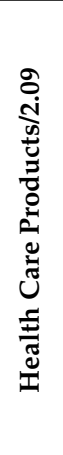 & 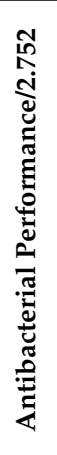 & 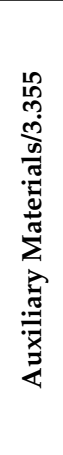 & 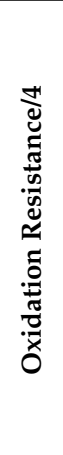 & 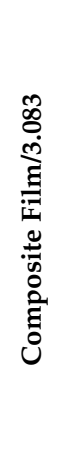 & 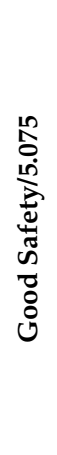 & 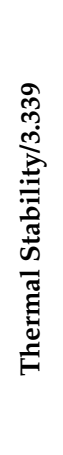 & 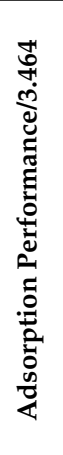 & 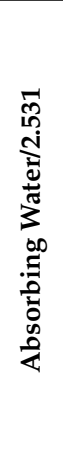 & 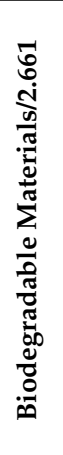 & 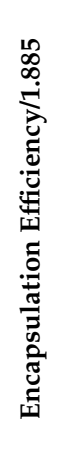 & 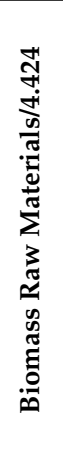 & 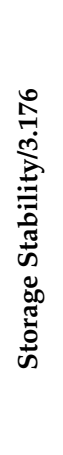 & 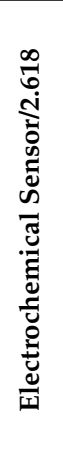 & 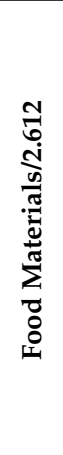 & 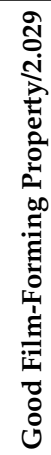 \\
\hline A61K & 14 & 7 & & 8 & 24 & 1 & 6 & 5 & & & & 2 & & 2 & 8 & & 1 & & & \\
\hline C08B & 10 & 14 & 3 & 1 & 8 & 4 & & & & & & 1 & & & & 2 & & & & \\
\hline $\mathrm{C} 12 \mathrm{~N}$ & 1 & & & & & & & & & 1 & 5 & & & & & & & & & \\
\hline B01J & & 1 & & & & & 2 & 1 & 1 & & & 8 & & & 2 & & & & & \\
\hline A61L & 19 & 3 & & 6 & & 7 & 1 & & & 9 & & & 5 & & 1 & & & & & \\
\hline $\mathrm{A} 01 \mathrm{~N}$ & 1 & 1 & 1 & 2 & 2 & 2 & & & & & & & & 1 & & & 2 & & 1 & \\
\hline C08L & 5 & 8 & 2 & 8 & 1 & 7 & & & 5 & & 3 & & 2 & 1 & & & 1 & & & 3 \\
\hline A23L & & & 14 & 1 & 10 & & 6 & 4 & 1 & & & & & & & & 1 & & 2 & 1 \\
\hline A23B & & & 26 & 3 & & & 1 & 4 & 2 & 1 & & & & & & & 1 & & 2 & \\
\hline C08J & 9 & 1 & 7 & 3 & & 2 & & 3 & 6 & & & & & 5 & & & 1 & & 2 & 2 \\
\hline $\mathrm{C} 05 \mathrm{G}$ & & 1 & 1 & 2 & & & 3 & & & & & & & & & 2 & & & & \\
\hline $\mathrm{C} 02 \mathrm{~F}$ & 2 & & & & & & & & & & & & & & & & & & & \\
\hline D06M & 1 & 8 & 1 & 6 & & 5 & 1 & & & & 2 & & & & & & & & & \\
\hline C12P & & 2 & & & & & & 1 & & & & & & & & & & & & \\
\hline A23K & & & 1 & & & 1 & & & & & & & & & & & & & & \\
\hline D01F & & 3 & & 2 & & 3 & & & & & & & & & & & & & & \\
\hline B01D & & 1 & & & & & & & 2 & & & 1 & & & & & & & & 1 \\
\hline C09D & & 2 & & 1 & & 1 & & & & & & & & & & & & & & \\
\hline G01N & 1 & & & & & & & & & & & & & & & & 2 & 6 & & \\
\hline $\mathrm{C} 08 \mathrm{~F}$ & 4 & & & & & & & & & 1 & & & & & & & & & & \\
\hline C09K & & & & & & & 1 & & & & & & & & & & & & & \\
\hline $\mathrm{D} 21 \mathrm{H}$ & 1 & 2 & & 2 & & 3 & & & & & & & & & & 1 & & & & \\
\hline C04B & 1 & & & 2 & & & & & & & & & & & & & & & & \\
\hline C07K & 1 & & & & & & & & & & & & & & & & & & & \\
\hline $\mathrm{A} 01 \mathrm{G}$ & & & & 1 & & & & & & & & & & & & & & & & \\
\hline C08G & & 1 & & 1 & & 2 & & & & & 1 & & & & & 3 & & & & \\
\hline H01M & & & & & & & & & & & 1 & & & & & & & & & \\
\hline
\end{tabular}


Table 3. Cont.

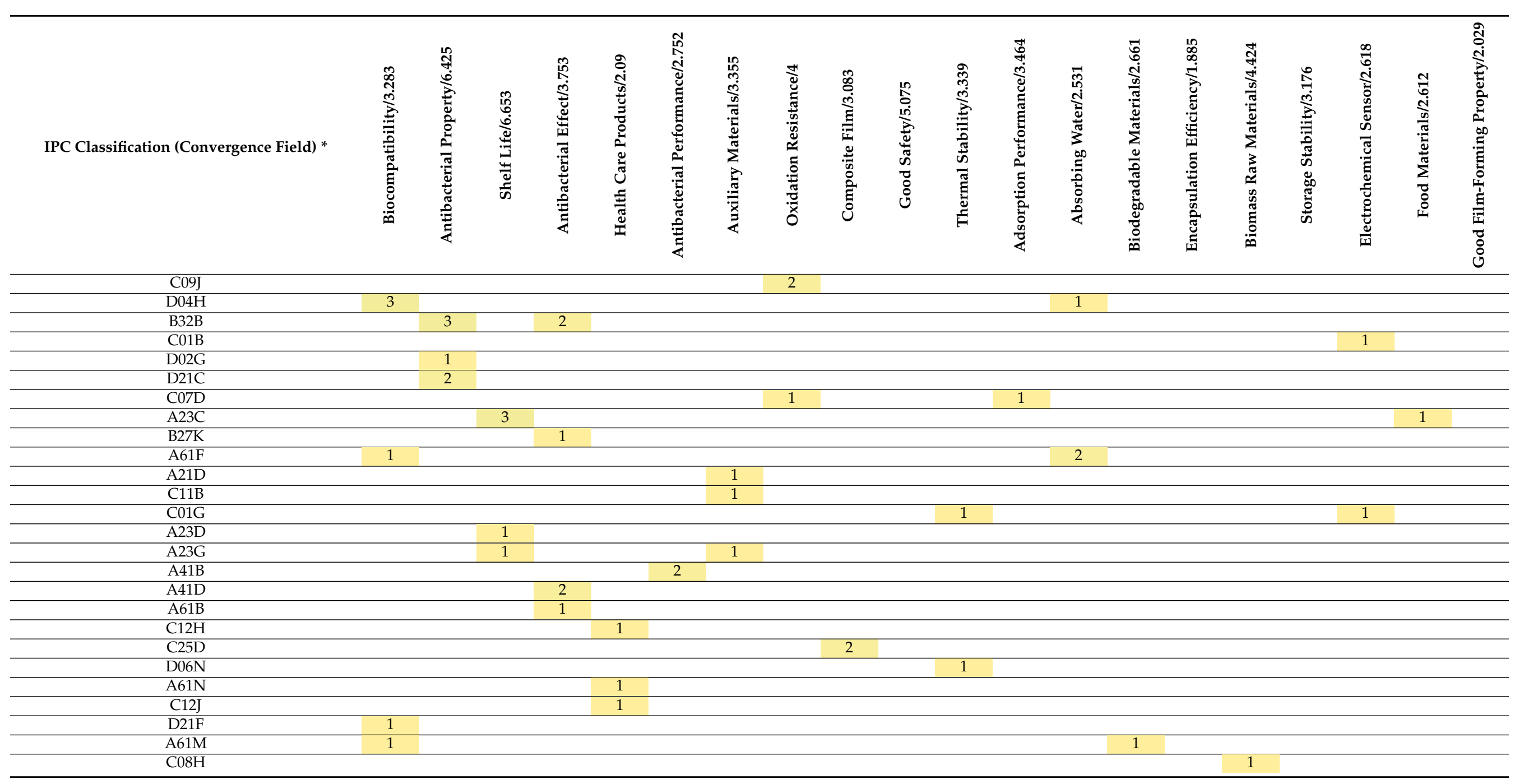

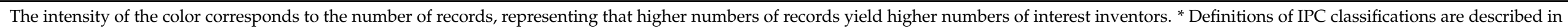
Appendix A. 
Firstly, the application of "shelf life" can be applied up to 10 IPCs, shown in Figure 6. Most patents applied for 1 to 3 IPCs; for example, 1 IPC accounts for $22 \%$, and more than $50 \%$ of patents aim to apply for a few IPCs. In other words, "shelf life" is a specific application because the most contribution of patents rely on only 1 IPC. However, some patents applied up to 10 IPCs. For example, the patent entitled "Method for preparing polysaccharide composite film by thermally stable recombinant bacterial laccase and application", describes that the composite film prepared by the method has high tensile strength and strong extensibility, has better antioxidant and antibacterial activities, and can effectively prolong the shelf life of fruits, vegetables, and meat products [76]. The target applications include the processing meat, poultry, or fish, manufacture of articles or shaped materials containing macromolecular substance, and microorganisms or enzymes for propagating, preserving, or maintaining microorganisms. Particularly, for example, classification A23B4/20 includes patent no. CN106259830A, which describes a microbial inhibiting, non-toxic preservative for frozen aquatic products prepared by compounding biological preservatives [77]. Under another attractive application, C08L97/02 (compositions of macromolecular compounds), patent $\mathrm{CN} 108690362 \mathrm{~A}$ covers an edible food packaging with antibacterial effects [78].

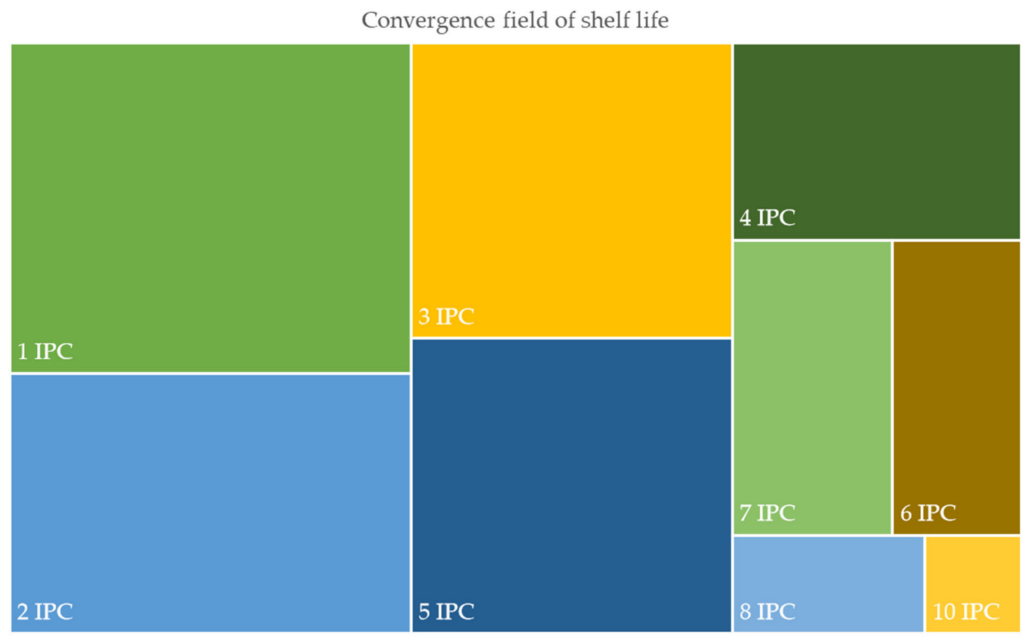

Figure 6. Convergence field of "shelf life".

Secondly, the application of "good safety" can be applied up to 7 IPCs, shown in Figure 7. Interestingly, no patent application applied only 1 IPC. They started from 2 IPCs (2 applications). The highest application for this field was 7 IPCs which accounted for $42 \%$ (the highest portion). This means that "good safety" applications are various, and most inventors aim to apply for many applications. The patent entitled "Hydrogel sponge xerogels superabsorbent polymer, method of making and applying it" applied for the highest applications [79]. This patent invented a polymer hydrogel xerogel sponge. The hydrogel xerogel sponge provided has the advantages of a simple preparation process and low cost. The product has outstanding hemostatic effect, good safety, with no heat production and no residue, and has significant medical value and industrial potential. Moreover, other patents were related to "good safety." The most popular application in this category is A61L24/08 (medical or veterinary science for sterilizing materials, disinfection, or deodorization of chemicals). For example, Guo et al. [80] describes a superabsorbent three-dimensional polymer hydrogel xerogel sponge with chitosan as its skeleton, a superabsorbent polymer as its branched chain, and a flexible macromolecule or polymer as its cross-linking agent. Like patent no. CN107050502A, the material can be used in the emergency hemostasis of large arteriovenous hemorrhage [81]. Wang [82] obtained a styptic powder made of chitosan and chitosan derivative that can reduce bleeding and prevent infection from pathogenic microorganisms. 
Convergence field of good safety

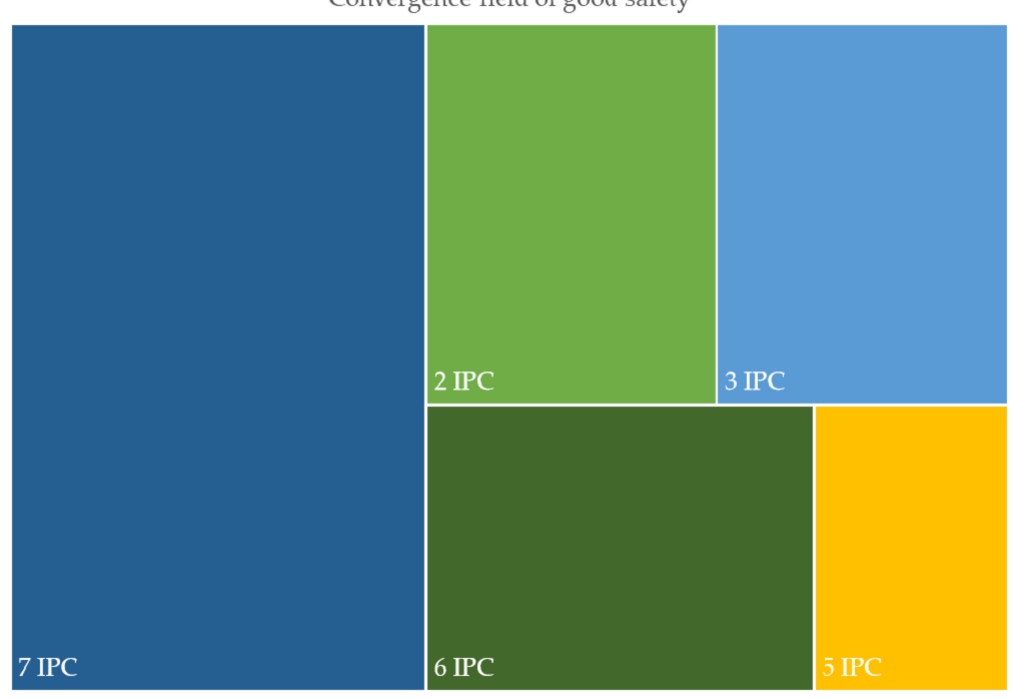

Figure 7. Convergence field of "good safety".

Thirdly, the application of "auxiliary materials" can be applied to up to 17 IPCs, as shown in Figure 8. This field contains various numbers of applications (IPCs) ranging from 1 IPC to 17 IPCs. The largest portions of IPCs in this field are 1 IPC and 3 IPCs and there is one patent that applied for 17 IPCs. This means that the application of this field is of interest in applying to inventors. The patent entitled "Method for improving immunopotentiation capacity of chitosan" [83] discloses a method for improving the immunopotentiation capacity of chitosan. Chitosan is used as a raw material, and radix codonopsis and ligusticum wallichii are used as auxiliary materials. The obtained chitosan-extracting solution can meet efficient utilization requirements of fields of health care, foods, and medicines. Furthermore, the most popular application is A61K31 (preparations for medical, dental, or toilet purposes containing an organic active ingredient). For example, patent no. CN103536595B offers an fast-absorbing acipimox composition capsule made of acipimox, chitosan nanoparticle, croscarmellose sodium, and hydroxypropyl methylcellulose [84]. Another application field for this emergent term is B01J13/00. For example, Ma et al. [85] show a highly absorbent, slow-releasing hydrogel that can be used as a facial mask, medical dressing, or tissue engineering scaffold.

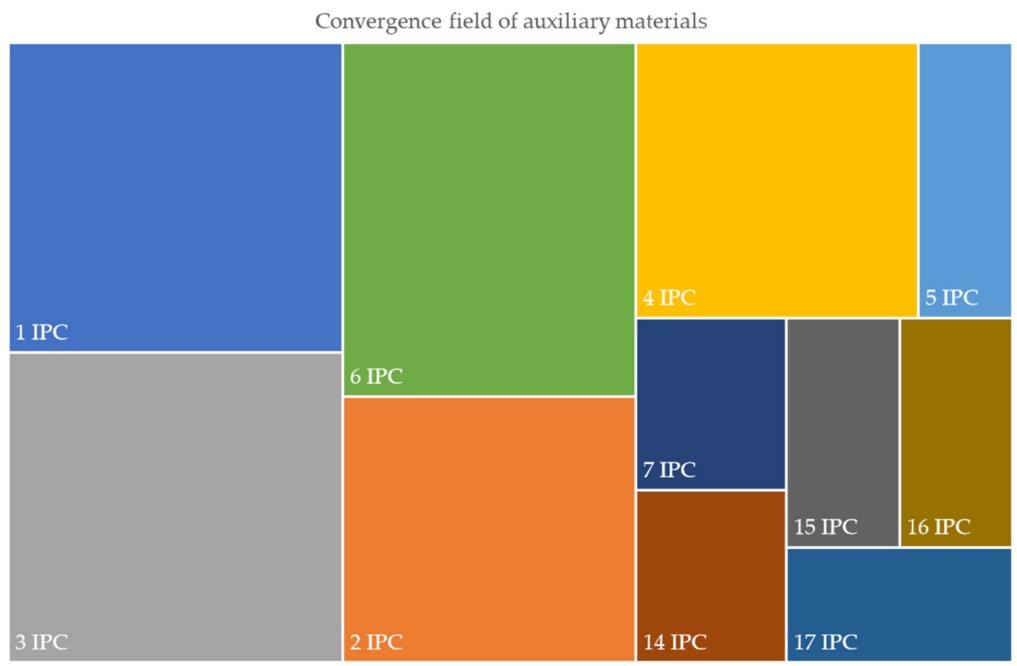

Figure 8. Convergence field of "auxiliary materials". 
Lastly, the applications associated with "absorbing water," are demonstrated in Figure 9. The highest number of applications is 5 IPCs, ranging from 2, 3, and 5 IPCs. This field has the lowest number of applications among the four emergent fields. The possible reason is that this field may only be applied for a specific application such as a medical application. For example, the most popular application is A61L15/28 (medical or veterinary science chemical aspects of, or use of materials for, bandages, dressings, or absorbent pads). For example, patent no. CN103239755A covers another multi-layered composite functional surgical dressing comprising a functional layer made of chitosan fiber and viscose that is in direct contact with the skin, a water-absorbing middle layer made of viscose, and a protective layer made of viscose and polyester fiber [72]. Like the invention of Wang et al. [86], this surgical dressing can be used to dress operative incisions, burns, ulcers, and other skin injuries.

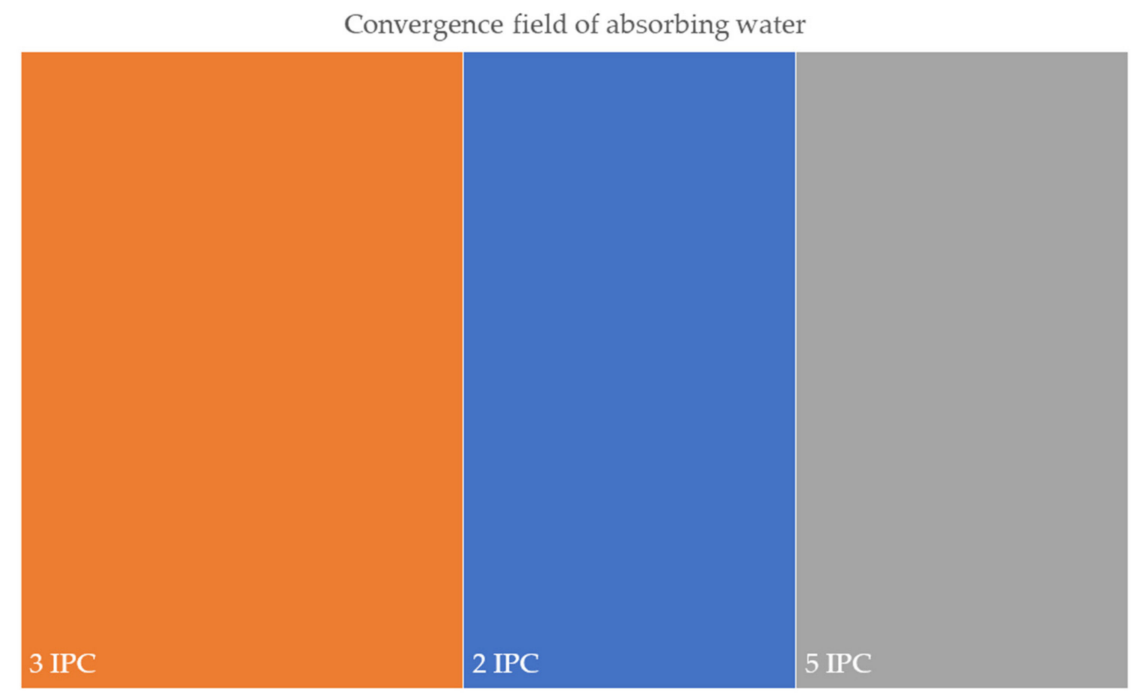

Figure 9. Convergence field of "absorbing water".

\subsubsection{Network Clustering}

VantagePoint software was used to construct the network or cluster map shown in Figure 10. The linkage lines denote joint research terms in which emergent terms are listed together. The nodes (yellow circles) indicate the number of terms (note that values are directly shown in cases when the numbers are too large for representation by a yellow circle). Terms related to antibacterial properties ("antibacterial effect", "antibacterial performance", and antibacterial property") were found to have a degree of centrality with other fields or applications. Indeed, "antibacterial effect" exhibited the highest degree of centrality, followed by "shelf life". Recently, studies applied antibacterial property as a base for development and convergence into other applications such as the study of emerging chitosan-based films for food packaging applications [24], promoting blood coagulation and full-thickness wound healing [87], as well as controlling bacterial pollution in water treatment [88]. In contrast, three terms that obtained low emergent scores, namely electrochemical sensor, biomass raw materials, and encapsulation efficiency, evinced no co-occurrences. Overall, the number of co-occurrences is not high compared with the numbers of patents. Interestingly, there are three terms (electrochemical sensor, biomass raw material, and encapsulation efficiency) that are not connected to other terms. These three terms would be terms newly linked to chitosan and could be potential new frontiers in clustering or linking with other terms for the application in the future. 


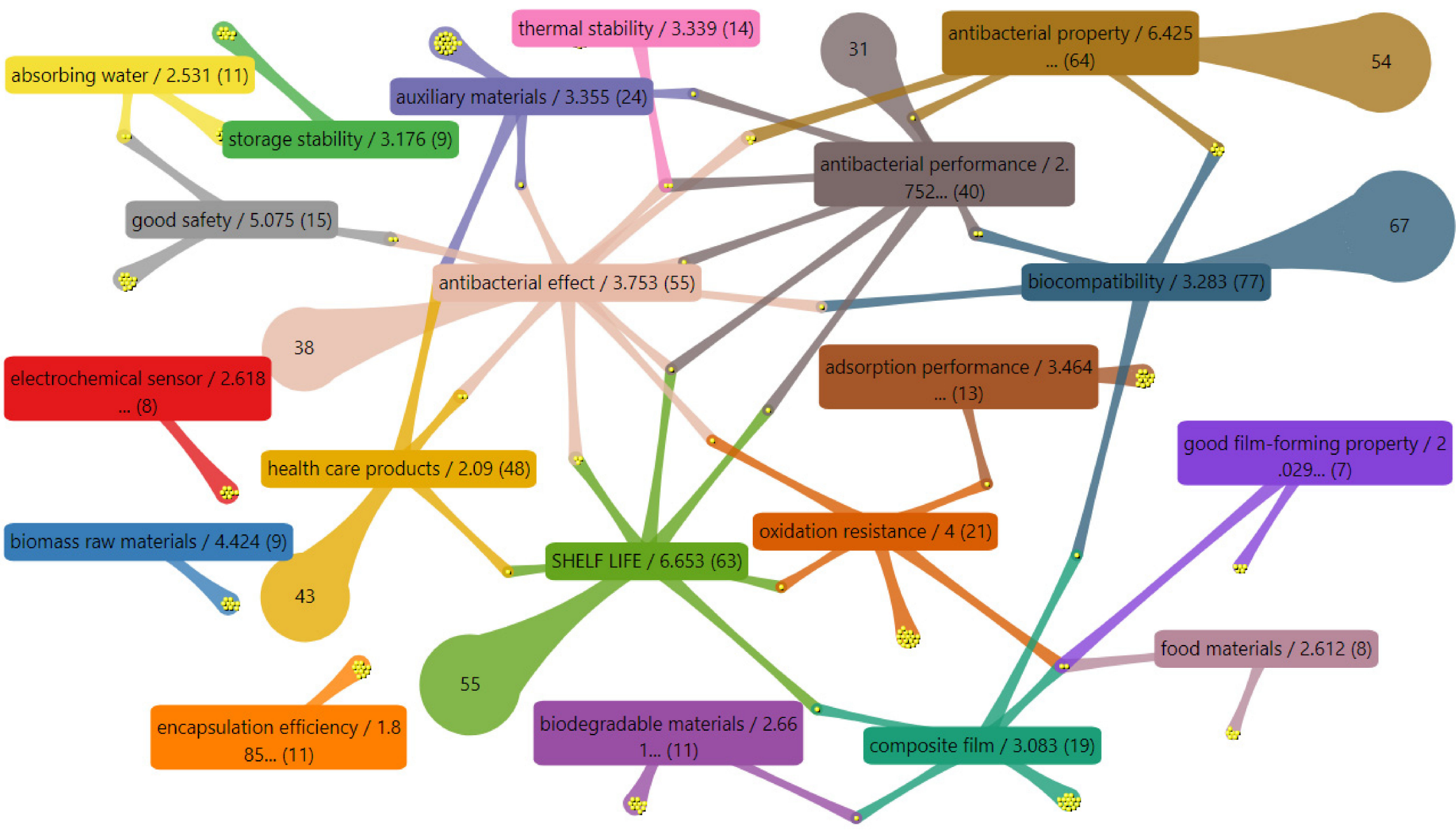

Figure 10. Cluster map of emergent topics. 


\section{Conclusions}

In this study, we applied a patent bibliometric predictive intelligence (PBPI) model to identify emergent topics and technology convergence related to chitosan applications from patents in the IPC classification system. An analysis of growth trends indicated that research in this area has intensified since 2008, and five major terms emerged in association with ascending and newly emergent topics: "shelf life", "antibacterial", "good safety", "absorbing water", and "auxiliary materials". These topics were closely linked with research in the biomedical and food production and preservation industries, and a network analysis indicated that "antibacterial" terms exhibited the highest degree of centrality, followed by "shelf life." Other terms such as electrochemical sensor, biomass raw material, and encapsulation efficiency that have not been linked to existing terms would be a new frontier for future research and development.

The results offer further evidence of the utility of analyzing the IPC system to identify major trends in research innovations of social and economic value [51,59]. In addition, the findings indicate that the PBPI model can provide companies with a comprehensive perspective of emergent topics and make informed decisions for $R \& D$ investment to gain a competitive advantage as first movers in the market. The PBPI model has been demonstrated to be valid in the case of chitosan biopolymer technology, particularly chitosan, and a number of emergent technologies using this material can be predicted in accordance with recent market trends. This methodology can be an effective tool for technology convergence and can be further developed to predict upcoming technological developments. Researchers can further adapt the model to fortify steps or algorithms for efficiently searching, analyzing, and presenting results.

In terms of practical implications, exploiting new business trends in chitosan applications not only strengthens economic growth, but also benefits the environment in terms of transforming waste from the fishery industry, particularly shrimp shells, into viable products or services. This study demonstrated the utility of technological convergence to identify emergent topics related to diverse chitosan applications for products and services in the healthcare, agriculture, and food and beverage industries. The identified patents provide a fruitful database to find research innovations leading to advanced technological applications. The increased number of patents on chitosan published during the last 10 years reflects the intensification of research on this topic, which in turn illustrates the potential of technological goals to stimulate socially responsible research. The major topics listed above are likely to remain particularly active areas for relevant companies to devote their technological development efforts. The large numbers of patents related to antibacterial and food preservation products aligns with findings reported throughout literature published in the last twenty years [89-92]. Moreover, the identification of newly emerging topics can help firms and research institutions identify major gaps and opportunities to strategize future directions of technological development in both new and existing markets. Companies can generate new products or services or devising innovative ways to develop existing items using chitosan as a raw material. The emergent topics can contribute to studies of product feasibility and thereby inform future investments. Organizations can direct the development of cutting-edge products and services in alignment with emerging business trends to gain a competitive advantage as first movers in expanding markets.

Additionally, the current research findings will help policymakers in designing and developing a more advanced and more efficient model for identifying emerging technologies. With these improvements due to technological advancements in the newly developed model in the future, collaborations will be intensified between the practitioners of this field. Research organizations and universities will be among the benefactors of these technological improvements of the model as its usability will be added to and will allow researchers to utilize the power of the model, thus getting more profound results in their research as they will get more insight into the applications of chitin/chitosan.

As mentioned in Section 2.2, patent bibliometric analysis has some limitations regarding its partial perspective of the entire research and development landscape, and the time 
lag due to the patent application process. Therefore, the analysis results may be different to the results from bibliometric analysis of research publication. For example, publication bibliometrics analysis and university researchers may find that the patent analysis results do not properly capture emerging topics of interest in the research community. In addition, it should be noted that top emergent topics such as "shelf life" and "antibacterial" are in fact the common themes of newer topics that may have lower emergent scores.

Recommendations for further analysis are provided. First, the sample being used has been limited to TotalPatent One database. The emerging study topics could be distributed in other databases. To have more insightful results, the future model should consider using multiple relevant databases, which could be considered more informative than using only one database. Second, this study is solely limited chitin/chitosan leaving aside other emerging technologies. The future model should incorporate other related emerging technologies. Finally, the results that are provided by the model directly relate to the input data provided by the user. Wrong input data will translate to wrong or misleading results. With regard to this, future model users should incorporate domain expertise knowledge for querying the right data for the model to provide sound and correct results.

Irrespective of the type of data being used, the structure of data, and its characteristics, the strength of the model is determined by its ability to use patents related to chitin/chitosan to identify the trends in the emerging technologies. The current results obtained from this model pave the way for future development plans to foster the processes of identification of the emerging technologies in the field of chitin/chitosan. The findings of the results cannot explain the discrepancies between the forecast made in the patents and the current opinion of the researchers reported in scientific literature about future perspectives in the chitosan area; the explanation of this discrepancy is that scientific articles and patent analysis lead to different findings. The objective of this paper was to investigate the emerging technologies from patents that are emerging or ready for commercialization or real utilization. For example, 'antibacterial' has been found in most publications but in real application identified by patents, it has been rarely observed. Thus, the conclusion for 'antibacterial' is that it is an emerging technology. Our interpretation is also supported by literature $[24,90,91]$. We noted that emerging technologies do not stay constant.

In addition, to alleviate this problem, the future developed model should analyze both publications and patents together to reduce the contradiction between the science and technology development, leading to the whole understanding of a particular technology. Additionally, the interpretation of results obtained from the model can be strengthened by experts in the field. The future model should ensure usability to interpret results with prior technological expertise or high level of domain knowledge.

Author Contributions: Conceptualization, N.M.; data curation, W.K.; formal analysis, W.K.; investigation, V.M.; methodology, W.K. and C.G.; supervision, V.M. and N.M.; validation, V.M. and N.M.; visualization, C.G.; writing—original draft, W.K.; writing—review and editing, C.G. and N.M. All authors have read and agreed to the published version of the manuscript.

Funding: This research received no external funding.

Institutional Review Board Statement: Not applicable.

Informed Consent Statement: Not applicable.

Data Availability Statement: Publicly available datasets were analyzed in this study. The data can be found here: https:/ / www.totalpatentone.com/, accessed on 2 May 2021.

Acknowledgments: This research was supported by the 100th Anniversary Chulalongkorn University Fund for Doctoral Scholarship as well as the Technopreneurship and Innovation Management Program, Graduate School, Chulalongkorn University, Thailand. We thank VantagePoint (version 12.0) software from Search Technology, Inc., Norcross, GA, USA, which greatly assisted the research and helped illustrate the outcome results of this study. Lastly, we would also like to show our gratitude to Urarika Luesakul for sharing her expertise on chitosan from both academic and industry perspectives during the conducting and interpreting of the research. 
Conflicts of Interest: The authors declare no conflict of interest.

\section{Appendix A}

Table A1. Definitions of IPC classifications.

A01G Human necessities -> agriculture; forestry; animal husbandry; hunting; trapping; fishing -> horticulture; cultivation of vegetables, flowers, rice, fruit, vines, hops or seaweed; forestry; watering

A01N Human necessities -> agriculture; forestry; animal husbandry; hunting; trapping; fishing -> preservation of bodies of humans or animals or plants or parts thereof; biocides

A21D Human necessities -> baking; equipment for making or processing doughs; doughs for baking -> treatment

A23B Human necessities -> foods or foodstuffs; treatment thereof, not covered by other classes $->$ preserving

A23C Human necessities $->$ foods or foodstuffs; treatment thereof, not covered by other classes $\rightarrow$ dairy products

A23D Human necessities -> foods or foodstuffs; treatment thereof, not covered by other classes -> edible oils or fats

A23G Human necessities -> foods or foodstuffs; treatment thereof, not covered by other classes -> cocoa; cocoa products

A23K Human necessities -> foods or foodstuffs; treatment thereof, not covered by other classes $->$ feeding-stuffs specially adapted for animals; methods specially adapted for production thereof

A23L Human necessities -> foods or foodstuffs; treatment thereof, not covered by other classes -> foods, foodstuffs, or non-alcoholic beverages, not covered by subclasses A21d or A23b-A23j; their preparation or treatment

A41B Human necessities -> wearing apparel -> shirts; underwear; baby linen; handkerchiefs

A41D Human necessities -> wearing apparel -> outerwear; protective garments; accessories

A61B Human necessities $->$ medical or veterinary science; hygiene $->$ diagnosis; surgery; identification

A61F Human necessities $->$ medical or veterinary science; hygiene $->$ filters implantable into blood vessels; prostheses; devices providing patency to, or preventing collapsing of, tubular structures of the body

A61K Human necessities -> medical or veterinary science; hygiene -> preparations for medical, dental, or toilet purposes

A61L Human necessities -> medical or veterinary science; hygiene -> methods or apparatus for sterilizing materials or objects in general; disinfection, sterilization, or deodorization of air; chemical aspects of bandages, dressings, absorbent pads, or surgical articles; materials for bandages, dressings, absorbent pads, or surgical articles

A61M Human necessities -> medical or veterinary science; hygiene -> devices for introducing media into, or onto, the body; devices for transducing body media or for taking media from the body; devices for producing or ending sleep or stupor

A61N Human necessities -> medical or veterinary science; hygiene -> electrotherapy; magnetotherapy; radiation therapy; ultrasound therapy

B01D Performing operations; transporting -> physical or chemical processes or apparatus in general -> separation

B01J Performing operations; transporting -> physical or chemical processes or apparatus in general -> chemical or physical processes

B27K Performing operations; transporting $->$ working or preserving wood or similar material; nailing or stapling machines in general -> processes, apparatus or selection of substances for impregnating, staining, dyeing or bleaching of wood, or for treating of wood with permeant liquids, not otherwise provided for; chemical or physical treatment of cork, cane, reed, straw or similar materials

B32B Performing operations; transporting $->$ layered products $->$ layered products

C01B Chemistry; metallurgy $->$ inorganic chemistry $->$ non-metallic elements; compounds thereof

C01G Chemistry; metallurgy $->$ inorganic chemistry $\rightarrow>$ compounds containing metals not covered by subclasses C01d or C01f

C02F Chemistry; metallurgy -> treatment of water, wastewater, sewage, or sludge -> treatment of water, wastewater, sewage, or sludge

C04B Chemistry; metallurgy -> cements; concrete; artificial stone; ceramics; refractories -> lime; magnesia; slag; cements; compositions thereof 
Table A1. Cont.

C05G Chemistry; metallurgy -> fertilizers; manufacture thereof -> mixtures of fertilizers covered individually by different subclasses of class c05; mixtures of one or more fertilizers with additives not having a specific fertilizing activity; fertilizers characterized by their form

C07D Chemistry; metallurgy $->$ organic chemistry $\rightarrow$ heterocyclic compounds

C07K Chemistry; metallurgy $->$ organic chemistry $->$ peptides

C08B Chemistry; metallurgy -> organic macromolecular compounds; their preparation or chemical working-up; compositions based thereon $->$ polysaccharides; derivatives thereof

C08F Chemistry; metallurgy $\rightarrow>$ organic macromolecular compounds; their preparation or chemical working-up; compositions based thereon -> macromolecular compounds obtained by reactions only involving carbon-to-carbon unsaturated bonds

C08G Chemistry; metallurgy $->$ organic macromolecular compounds; their preparation or chemical working-up; compositions based thereon -> macromolecular compounds obtained otherwise than by reactions only involving carbon-to-carbon unsaturated bonds

$\mathrm{C} 08 \mathrm{H}$ Chemistry; metallurgy -> organic macromolecular compounds; their preparation or chemical working-up; compositions based thereon $->$ derivatives of natural macromolecular compounds

C08J Chemistry; metallurgy -> organic macromolecular compounds; their preparation or chemical working-up; compositions based thereon -> working-up; general processes of compounding; after-treatment not covered by subclasses C08b, C08c, C08f, C08g or C08h

C08L Chemistry; metallurgy -> organic macromolecular compounds; their preparation or chemical working-up; compositions based thereon $->$ compositions of macromolecular compounds

C09D Chemistry; metallurgy -> dyes; paints; polishes; natural resins; adhesives; compositions not otherwise provided for; applications of materials not otherwise provided for $\rightarrow>$ coating compositions

C09J Chemistry; metallurgy -> dyes; paints; polishes; natural resins; adhesives; compositions not otherwise provided for; applications of materials not otherwise provided for $->$ adhesives; non-mechanical aspects of adhesive processes in general; adhesive processes not provided for elsewhere; use of materials as adhesives

C09K Chemistry; metallurgy -> dyes; paints; polishes; natural resins; adhesives; compositions not otherwise provided for; applications of materials not otherwise provided for $->$ materials for applications not otherwise provided for; applications of materials not otherwise provided for

C11B Chemistry; metallurgy -> animal or vegetable oils, fats, fatty substances, or waxes; fatty acids therefrom; detergents; candles $\rightarrow$ producing

$\mathrm{C} 12 \mathrm{H} \quad$ Chemistry; metallurgy -> biochemistry; beer; spirits; wine; vinegar; microbiology; enzymology; mutation or genetic engineering -> pasteurization, sterilization, preservation, purification, clarification or ageing of alcoholic beverages; methods for altering the alcohol content of fermented solutions or alcoholic beverages

C12J Chemistry; metallurgy -> biochemistry; beer; spirits; wine; vinegar; microbiology; enzymology; mutation or genetic engineering -> vinegar; preparation or purification thereof

C12N Chemistry; metallurgy -> biochemistry; beer; spirits; wine; vinegar; microbiology; enzymology; mutation or genetic engineering -> microorganisms or enzymes; compositions thereof; propagating, preserving, or maintaining microorganisms; mutation or genetic engineering; culture media

C12P Chemistry; metallurgy -> biochemistry; beer; spirits; wine; vinegar; microbiology; enzymology; mutation or genetic engineering -> fermentation or enzyme-using processes to synthesize a desired chemical compound or composition or to separate optical isomers from a racemic mixture

C25D Chemistry; metallurgy -> electrolytic or electrophoretic processes; apparatus therefor -> processes for the electrolytic or electrophoretic production of coatings; electroforming; joining workpieces by electrolysis; apparatus therefor

D01F Textiles; paper -> natural or man-made threads or fibers; spinning -> chemical features in the manufacture of man-made filaments, threads, fibers, bristles, or ribbons; apparatus specially adapted for the manufacture of carbon filaments

D02G Textiles; paper -> yarns; mechanical finishing of yarns or ropes; warping or beaming -> crimping or curling fibers, filaments, yarns, or threads; yarns or threads

D04H Textiles; paper -> braiding; lace making; knitting; trimmings; non-woven fabrics -> making textile fabrics

D06M Textiles; paper -> treatment of textiles or the like; laundering; flexible materials not otherwise provided for -> treatment, not provided for elsewhere in class D06, of fibers, threads, yarns, fabrics, feathers, or fibrous goods made from such materials 
Table A1. Cont.
D06N
Textiles; paper -> treatment of textiles or the like; laundering; flexible materials not otherwise provided for -> wall, floor, or like covering materials
D21C Textiles; paper -> paper making; production of cellulose -> production of cellulose by removing non-cellulose substances from cellulose-containing materials; regeneration of pulping liquors; apparatus therefor
D21F Textiles; paper -> paper making; production of cellulose -> paper-making machines; methods of producing paper thereon
D21H Textiles; paper -> paper making; production of cellulose -> pulp compositions; preparation thereof not covered by subclasses d21c, d21d; impregnating or coating of paper; treatment of finished paper not covered by class B31 or subclass D21g; paper not otherwise provided for
G01N Physics -> measuring; testing -> investigating or analyzing materials by determining their chemical or physical properties
H01M Electricity $->$ basic electric elements $->$ processes or means

\section{References}

1. Lei, D.T. Industry evolution and competence development: The imperatives of technological convergence. Int. J. Technol. Manag. 2000, 19, 699-738. [CrossRef]

2. Martin, B.R. Foresight in science and technology. Technol. Anal. Strateg. Manag. 1995, 7, 139-168. [CrossRef]

3. Daim, T.U.; Rueda, G.; Martin, H.; Gerdsri, P. Forecasting emerging technologies: Use of bibliometrics and patent analysis. Technol. Forecast. Soc. Chang. 2006, 73, 981-1012. [CrossRef]

4. Curran, C.-S.; Leker, J. Patent indicators for monitoring convergence-Examples from NFF and ICT. Technol. Forecast. Soc. Chang. 2011, 78, 256-273. [CrossRef]

5. Karvonen, M.; Kässi, T. Patent analysis for analysing technological convergence. Foresight 2011, 13, 34-50. [CrossRef]

6. Karvonen, M.; Kässi, T. Patent citations as a tool for analysing the early stages of convergence. Technol. Forecast. Soc. Chang. 2013, 80, 1094-1107. [CrossRef]

7. Goeldner, M.; Herstatt, C.; Tietze, F. The emergence of care robotics-A patent and publication analysis. Technol. Forecast. Soc. Chang. 2015, 92, 115-131. [CrossRef]

8. Lee, W.S.; Han, E.J.; Sohn, S.Y. Predicting the pattern of technology convergence using big-data technology on large-scale triadic patents. Technol. Forecast. Soc. Chang. 2015, 100, 317-329. [CrossRef]

9. Sen, S.K.; Sharma, H.P. A note on growth of superconductivity patents with two new indicators. Inf. Process. Manag. 2006, 42, 1643-1651. [CrossRef]

10. Lukatch, R.; Plasmans, J. Measuring Knowledge Spillovers Using Patent Citations: Evidence from Belgian Firms' Data; CESifo Working Paper, No. 754; Center for Economic Studies and ifo Institute (CESifo): Munich, Germany, 2002.

11. Han, Y.-J.; Park, Y. Patent network analysis of inter-industrial knowledge flows: The case of Korea between traditional and emerging industries. World Pat. Inf. 2006, 28, 235-247. [CrossRef]

12. Allarakhia, M.; Walsh, S. Analyzing and organizing nanotechnology development: Application of the institutional analysis development framework to nanotechnology consortia. Technovation 2012, 32, 216-226. [CrossRef]

13. Rao, M.G.; Bharathi, P.; Akila, R. A comprehensive review on biopolymers. Sci. Revs. Chem. Commun. 2014, 4, 61-68.

14. Ibrahim, S.; Riahi, O.; Said, S.M.; Sabri, M.F.M.; Rozali, S. Biopolymers From Crop Plants. In Reference Module in Materials Science and Materials Engineering; Elsevier: Amsterdam, The Netherlands, 2019.

15. Sanchez-Vazquez, S.; Hailes, H.; Evans, J. Hydrophobic polymers from food waste: Resources and synthesis. Polym. Rev. 2013, 53, 627-694. [CrossRef]

16. Moradali, M.F.; Rehm, B.H. Bacterial biopolymers: From pathogenesis to advanced materials. Nat. Rev. Microbiol. 2020, 18, 195-210. [CrossRef]

17. Klongthong, W.; Muangsin, V.; Gowanit, C.; Muangsin, N. Chitosan Biomedical Applications for the Treatment of Viral Disease: A Data Mining Model Using Bibliometric Predictive Intelligence. J. Chem. 2020, 2020, 6612034. [CrossRef]

18. Khan, T.; Park, J.K.; Kwon, J.-H. Functional biopolymers produced by biochemical technology considering applications in food engineering. Korean J. Chem. Eng. 2007, 24, 816-826. [CrossRef]

19. Correlo, V.M.; Boesel, L.F.; Bhattacharya, M.; Mano, J.F.; Neves, N.M.; Reis, R.L. Properties of melt processed chitosan and aliphatic polyester blends. Mater. Sci. Eng. A 2005, 403, 57-68. [CrossRef]

20. Soukoulis, C.; Gaiani, C.; Hoffmann, L. Plant seed mucilage as emerging biopolymer in food industry applications. Curr. Opin. Food Sci. 2018, 22, 28-42. [CrossRef]

21. Reddy, N.; Reddy, R.; Jiang, Q. Crosslinking biopolymers for biomedical applications. Trends Biotechnol. 2015, 33, 362-369. [CrossRef]

22. Yadav, P.; Yadav, H.; Shah, V.G.; Shah, G.; Dhaka, G. Biomedical biopolymers, their origin and evolution in biomedical sciences: A systematic review. J. Clin. Diagn. Res. JCDR 2015, 9, ZE21. [CrossRef] 
23. Moohan, J.; Stewart, S.A.; Espinosa, E.; Rosal, A.; Rodríguez, A.; Larrañeta, E.; Donnelly, R.F.; Domínguez-Robles, J. Cellulose nanofibers and other biopolymers for biomedical applications. A review. Appl. Sci. 2020, 10, 65. [CrossRef]

24. Wang, H.; Qian, J.; Ding, F. Emerging chitosan-based films for food packaging applications. J. Agric. Food Chem. 2018, 66, 395-413. [CrossRef]

25. Sahoo, D.; Sahoo, S.; Mohanty, P.; Sasmal, S.; Nayak, P.L. Chitosan: A New Versatile Bio-polymer for Various Applications. Des. Monomers Polym. 2009, 12, 377-404. [CrossRef]

26. Shukla, S.K.; Mishra, A.K.; Arotiba, O.A.; Mamba, B.B. Chitosan-based nanomaterials: A state-of-the-art review. Int. J. Biol. Macromol. 2013, 59, 46-58. [CrossRef]

27. De Haan, J. How emergence arises. Ecol. Complex. 2006, 3, 293-301. [CrossRef]

28. Goldstein, J. Emergence as a Construct: History and Issues. Emergence 1999, 1, 49-72. [CrossRef]

29. Day, G.S.; Schoemaker, P.J.H.; Gunther, R.E. Wharton on Managing Emerging Technologies; John Wiley \& Sons: New York, NY, USA, 2000 .

30. Porter, A.L. How Tech Mining Works; John Wiley \& Sons: New York, NY, USA, 2004; pp. 17-32.

31. Porter, A.L.; Detampel, M.J. Technology opportunities analysis. Technol. Forecast. Soc. Chang. 1995, 49, 237-255. [CrossRef]

32. Srinivasan, R. Sources, characteristics and effects of emerging technologies: Research opportunities in innovation. Ind. Mark. Manag. 2008, 37, 633-640. [CrossRef]

33. Porter, A.L.; Roessner, J.D.; Jin, X.-Y.; Newman, N.C. Measuring national 'emerging technology' capabilities. Sci. Public Policy 2002, 29, 189-200. [CrossRef]

34. Glänzel, W.; Thijs, B. Using 'core documents' for detecting and labelling new emerging topics. Scientometrics 2012, 91, 399-416. [CrossRef]

35. Boyack, K.W.; Klavans, R.; Small, H.; Ungar, L. Characterizing the emergence of two nanotechnology topics using a contemporaneous global micro-model of science. J. Eng. Technol. Manag. 2014, 32, 147-159. [CrossRef]

36. Huang, Y.; Schuehle, J.; Porter, A.L.; Youtie, J. A systematic method to create search strategies for emerging technologies based on the Web of Science: Illustrated for 'Big Data'. Scientometrics 2015, 105, 2005-2022. [CrossRef]

37. Cho, T.-S.; Shih, H.-Y. Patent citation network analysis of core and emerging technologies in Taiwan: 1997-2008. Scientometrics 2011, 89, 795. [CrossRef]

38. Kyebambe, M.N.; Cheng, G.; Huang, Y.; He, C.; Zhang, Z. Forecasting emerging technologies: A supervised learning approach through patent analysis. Technol. Forecast. Soc. Chang. 2017, 125, 236-244. [CrossRef]

39. Upham, S.P.; Small, H. Emerging research fronts in science and technology: Patterns of new knowledge development. Scientometrics 2010, 83, 15-38. [CrossRef]

40. Porter, A.L.; Garner, J.; Carley, S.F.; Newman, N.C. Emergence scoring to identify frontier R\&D topics and key players. Technol. Forecast. Soc. Chang. 2019, 146, 628-643. [CrossRef]

41. Geum, Y.; Kim, M. How to identify promising chances for technological innovation: Keygraph-based patent analysis. Adv. Eng. Inform. 2020, 46, 101155. [CrossRef]

42. Day, G.S.; Schoemaker, P.J.H. Avoiding the Pitfalls of Emerging Technologies. Calif. Manag. Rev. 2000, 42, 8-33. [CrossRef]

43. Small, H.; Boyack, K.W.; Klavans, R. Identifying emerging topics in science and technology. Res. Policy 2014, 43, 1450-1467. [CrossRef]

44. Stahl, B.C. What Does the Future Hold? A Critical View of Emerging Information and Communication Technologies and Their Social Consequences. In Researching the Future in Information Systems; Springer: Berlin/Heidelberg, Germany, 2011 ; pp. 59-76.

45. Alexander, J.; Chase, J.; Newman, N.; Porter, A.L.; Roessner, J.D. Emergence as a conceptual framework for understanding scientific and technological progress. In Proceedings of the 2012 Proceedings of PICMET'12: Technology Management for Emerging Technologies, Vancouver, BC, Canada, 29 July-2 August 2012; pp. 1286-1292.

46. Ena, O.; Mikova, N.; Saritas, O.; Sokolova, A. A methodology for technology trend monitoring: The case of semantic technologies. Scientometrics 2016, 108, 1013-1041. [CrossRef]

47. Cavaller, V. Limits of analytical instruments in technology watch: Application of a practical case in biotechnology. e-SOCIETY 2007, 2007, 203-211.

48. Jürgens, B.; Herrero-Solana, V. Patent bibliometrics and its use for technology watch. J. Intell. Stud. Bus. 2017, 7, 17-26. [CrossRef]

49. Chang, S.-H. Analyses of the Key Technologies and Development Trends of Optical Networks from the Perspective of Standard Essential Patents. Appl. Sci. 2021, 11, 1583. [CrossRef]

50. Chang, S.-H. Patent Analysis of the Critical Technology Network of Semiconductor Optical Amplifiers. Appl. Sci. 2020, 10, 1552. [CrossRef]

51. Leydesdorff, L. Patent classifications as indicators of intellectual organization. J. Am. Soc. Inf. Sci. Technol. 2008, 59, 1582-1597. [CrossRef]

52. Koo, Y.; Cho, K. The Relationship between Patents, Technology Transfer and Desorptive Capacity in Korean Universities. Sustainability 2021, 13, 5253. [CrossRef]

53. Cho, Y.; Han, Y.J.; Hwang, J.; Yu, J.; Kim, S.; Lee, C.; Lee, S.; Yi, K.P. Identifying Technology Opportunities for Electric Motors of Railway Vehicles with Patent Analysis. Sustainability 2021, 13, 2424. [CrossRef]

54. Lee, S.; Park, G.; Yoon, B.; Park, J. Open innovation in SMEs-An intermediated network model. Res. Policy 2010, 39, 290-300. [CrossRef] 
55. Ko, S.-S.; Ko, N.; Kim, D.; Park, H.; Yoon, J. Analyzing technology impact networks for R\&D planning using patents: Combined application of network approaches. Scientometrics 2014, 101, 917-936. [CrossRef]

56. Han, E.J.; Sohn, S.Y. Technological convergence in standards for information and communication technologies. Technol. Forecast. Soc. Chang. 2016, 106, 1-10. [CrossRef]

57. Yun, J.; Geum, Y. Automated classification of patents: A topic modeling approach. Comput. Ind. Eng. 2020, 147, 106636. [CrossRef]

58. Gao, F.; Chen, D.-L.; Weng, M.-H.; Yang, R.-Y. Revealing Development Trends in Blockchain-Based 5G Network Technologies through Patent Analysis. Sustainability 2021, 13, 2548. [CrossRef]

59. Wang, Z.; Porter, A.L.; Wang, X.; Carley, S. An approach to identify emergent topics of technological convergence: A case study for 3D printing. Technol. Forecast. Soc. Chang. 2019, 146, 723-732. [CrossRef]

60. Klongthong, W.; Muangsin, N.; Gowanit, C.; Muangsin, V. Technological convergence: The analysis of emergent topics on chitosan. In Proceedings of the ISPIM Connects Bangkok-Partnering for an Innovative Community, Bangkok, Thailand, 1-4 March 2020; ISPIM: Bangkok, Thailand, 2020.

61. Porter, A.L.; Cunningham, S.W.; Bank, J.; Roper, A.T.; Mason, T.W.; Rossini, F.A. Forecasting and Management of Technology, 2nd ed.; John Wiley \& Sons: New York, NY, USA, 2011.

62. Chang, P.-L.; Wu, C.-C.; Leu, H.-J. Using patent analyses to monitor the technological trends in an emerging field of technology: A case of carbon nanotube field emission display. Scientometrics 2010, 82, 5-19. [CrossRef]

63. Yoon, J.; Kim, K. Identifying rapidly evolving technological trends for R\&D planning using SAO-based semantic patent networks. Scientometrics 2011, 88, 213-228. [CrossRef]

64. Huang, Y.; Zhu, D.; Qian, Y.; Zhang, Y.; Porter, A.L.; Liu, Y.; Guo, Y. A hybrid method to trace technology evolution pathways: A case study of 3D printing. Scientometrics 2017, 111, 185-204. [CrossRef]

65. Chang, D. Edible Packaging Film Based on Chitosan and Preparation Method Thereof. CN106046402B, 20 August 2019.

66. Zhong, Y.; Deng, Y.; Yue, J.; Zhu, G.; Zhuang, C.; Wang, D.; Jiang, Y.; Bao, E. Egg Product Freshness Keeping Method by Means of Double Layers of Nano-Antibacterial Coating Films. CN105166010A, 23 December 2015.

67. Chen, Z.; Gao, Z.; Yang, Y. Antibacterial Agent Composition and Application. CN111066792A, 28 April 2020.

68. Zhao, Y.; Du, Y.; Xu, Z. A Composite Chitosan Bacteriostatic Food Packaging Paper Preparation Method and Application. CN106436473B, 3 November 2017.

69. Dong, F.; Li, S.; Lu, H.; Li, X.; Wang, X.; Liu, Z. A Silver-Loaded Nano Cellulose-Chitosan Composite Membrane Preparation Method. CN106832437B, 28 May 2019.

70. Guo, X.; Qian, Z.; Tuo, X. A Super Absorbent Polymer Hydrogel Adhesive Sponge and Its Preparation and Use. CN107050502B, 27 November 2018.

71. Zhang, H.; Xiao, J.; Xu, K.; Wu, J. Breathable Moisture-Absorbing Type Wound Plaster. CN110403760A, 5 November 2019.

72. Jin, X.; Wu, H.; Wu, J.; Yin, B.; Wang, R.; Wang, H.; Zhang, C. Method for Preparing Multi-Layer Composite Functional Surgical Dressing. CN103239755A, 14 August 2013.

73. Cui, X.; Zhang, C.; Chu, F.; Jiang, G.; Fan, S.; Yao, W.; Wang, B.; Yan, Z.; Wang, J. Antiviral Soil-Fixing Dust Suppressant as Well as Preparation Method and Application Thereof. CN112111248A, 22 December 2020.

74. Wang, D.; Kang, X.; Xu, Z. Ecological Organic Fertilizer as Well as Preparation Method and Application Thereof. CN108395324A, 14 August 2018.

75. World Intellectual Property Organisation. International Patent Classification (IPC). Available online: https://www.wipo.int/ classifications/ipc/en/ (accessed on 15 April 2021).

76. Zhang, C.; Bu, G.; Zhang, X. Method for Preparing Polysaccharide Composite Film by Thermally Stable Recombinant Bacterial Laccase and Application. CN110240720A, 17 September 2019.

77. Li, J. Formula of Aquatic Product Composite Preservative. CN106259830A, 4 January 2017.

78. Edible Fruit Peel Packaging Paper and Preparation Method Thereof. CN108690362A, 23 October 2018.

79. Guo, X.; Qian, Z.; Tuo, X. Hydrogel Sponge Xerogels Superabsorbent Polymer, Method of Making and Applying It. BRPI1912801A2, 3 December 2019.

80. Guo, X.; Qian, Z.; Tuo, X. Dry Gel Sponge of Super Water-Absorbent Polymer Hydrogel, Preparation Method Therefor and Use Thereof. EP3560524A1, 30 October 2019.

81. Guo, X.; Qian, Z.; Tuo, X. Macromolecule Hydrogel Dry Glue Sponge with Super Water Absorption, and Preparation Method and Application Thereof. CN107050502A, 18 August 2017.

82. Wang, Y. Bleeding Stopping Powder and Preparation Method Thereof. CN110755674A, 7 February 2020.

83. Liang, Z.; Wang, G.; Sun, Q.; Wang, X. Method for Improving Immunopotentiation Capacity of Chitosan. CN111449245A, 28 July 2020.

84. Wang, L.; Wang, J.; Xiao, Q. Acipimox Composition Tablet. CN103536595B, 22 April 2015.

85. Ma, J.; Jin, H.; Chen, J.; Xi, Y.; Zhu, Y.; Zhou, X.; Hu, T.; Jin, Y.; Ding, S.; Tan, L. Attapulgite-Chitosan Composite Gel and Preparation Method Thereof. CN109158058A, 8 January 2019.

86. Wang, Q.; Jin, X.; Gu, Q.; Wu, J.; Wang, Y.; Wu, H.; Yin, B.; Wang, R.; Wang, H.; Zhang, C. Method for Preparing Multi-Layer Composite Functional Surgical Dressing. CN103239755B, 22 April 2015. 
87. He, Y.; Zhao, W.; Dong, Z.; Ji, Y.; Li, M.; Hao, Y.; Zhang, D.; Yuan, C.; Deng, J.; Zhao, P. A biodegradable antibacterial alginate/carboxymethyl chitosan/Kangfuxin sponges for promoting blood coagulation and full-thickness wound healing. Int. J. Biol. Macromol. 2021, 167, 182-192. [CrossRef]

88. Li, X.; Sun, J.; Che, Y.; Lv, Y.; Liu, F. Antibacterial properties of chitosan chloride-graphene oxide composites modified quartz sand filter media in water treatment. Int. J. Biol. Macromol. 2019, 121, 760-773. [CrossRef] [PubMed]

89. No, H.; Meyers, S.P.; Prinyawiwatkul, W.; Xu, Z. Applications of chitosan for improvement of quality and shelf life of foods: A review. J. Food Sci. 2007, 72, R87-R100. [CrossRef]

90. Romanazzi, G.; Feliziani, E.; Baños, S.B.; Sivakumar, D. Shelf life extension of fresh fruit and vegetables by chitosan treatment. Crit. Rev. Food Sci. Nutr. 2017, 57, 579-601. [CrossRef]

91. Verlee, A.; Mincke, S.; Stevens, C.V. Recent developments in antibacterial and antifungal chitosan and its derivatives. Carbohydr. Polym. 2017, 164, 268-283. [CrossRef]

92. Ke, C.-L.; Deng, F.-S.; Chuang, C.-Y.; Lin, C.-H. Antimicrobial Actions and Applications of Chitosan. Polymers 2021, $13,904$. [CrossRef] 